\title{
An overview of CAR T cell mediated B cell Maturation Antigen therapy
}

\section{Sameer Quazi ${ }^{1}$}

1. Founder \& CEO, GenLab Biosolutions Private Limited, Bangalore, Karnataka, India. (560043)

Email: Colonel.quazi@gmail.com

\begin{abstract}
:
Multiple Myeloma (MM) is one of the incurable types of cancer in plasma cells. While immense progress has been made in the treatment of this malignancy, a large percentage of patients were unable to adapt to such therapy. Additionally, these therapies might be associated with significant diseases and are not always tolerated well in all patients. Since cancer in plasma cells has no cure, patients develop resistance to treatments, resulting in $\mathrm{R} / \mathrm{R}$ MM. BCMA is primarily produced on mature B cells. Its up-regulation and activation are associated with multiple myeloma in both murine and human models, indicating that this might be an effective therapeutic target for this type of malignancy. Additionally, BCMA's predictive value, association with effective clinical trials, and capacity to be utilized in previously difficult to observe patient populations, imply that it might be used as a biomarker for multiple myeloma. Numerous kinds of BCMA-targeting medicines have demonstrated antimyeloma efficacy in individuals with refractory/relapsed MM, including CAR T-cell treatments, ADCs, bispecific antibody constructs. Among these medications, CART cell-mediated BCMA therapy has shown significant outcomes in multiple myeloma clinical trials. This review article outlines CAR T cell mediated BCMA medicines have the efficiency to change the therapeutic pattern for multiple myeloma significantly.
\end{abstract}

Keywords: BCMA, CAR T cell, Multiple Myeloma, Refractory/Relapsed, ADCs, Bispecific Antibody. 


\section{Highlights:}

1. CAR T cell mediated BCMA therapy has brought revolutionary changes in multiple myeloma treatment.

2. There are three kinds of therapeutic agents against multiple myeloma such as CAR T cell s, bispecific antibody constructs and antibody drug conjugate.

3. The phase 1 clinical trial of CAR T cell therapy have exhibited high response rates in patients with RRMM.

4. Currently, twenty-six clinical trials are recruiting patients for CAR T cell mediated BCMA medication.

5. To reduce cytotoxicity and neurotoxicity, genetically modified CAR T cells can be utilized in BCMA targeted treatment.

\section{Abbreviation:}

MM: Multiple myeloma

BCMA: B cell maturation antigen

APRIL: A proliferation-inducing ligand

BAFF: B cell activating factor

BiTE: Bispecific T cell engager

ASCT: Autologous or allogenic stem cell transplantation

CR: Complete response

CRS: Cytokine release syndrome

PI: Proteasome inhibitor

PR: Partial response

$\mathrm{R} / \mathrm{R}$ : Relapsed and/or refractory

sCR: Stringent complete response

VGPR: Very good partial response

DLT: Dose-limiting toxicity

DOF: Duration of follow-up

FAMP: Fludarabine
IMiD: Immunomodulatory imide drug

CTX: Cyclophosphamide

ORR: Overall response rate

OS: Overall survival

ADCC: Antibody-dependent cell-mediated cytotoxicity

mAb: Monoclonal antibodies

mDOR: Median duration of response

mPFS: Median progression-free survival

MRD: Minimal residual disease

MTD: Maximal tolerated dose

NTX: Neurotoxicity

PC: Plasma cell

ADC:Antibody-drug conjugate

PD:Progressive disease 


\section{Introduction:}

The advancement of chimeric antigen receptor $\mathrm{T}$ cell treatment has prevailed significant promising outcomes in immunotherapy over the past decades. It has risen as one of the most propitious areas of cancer therapy because of its outstanding outcomes in hematological malignancies and intriguing pre-clinical anti-tumor efficacy against a wide variety of solid tumors. The first chimeric antigen receptor T cell immunotherapies; Kymriah and Yescarta were authorized by the FDA due to their effectiveness in treating B cell malignancies [1]. Kymirah and Yescarta can target CD19 to cure adults with large B cell lymphoma and children with B lymphoblastic leukaemia . In 2020 and 2021, the FDA authorized two more CAR-T cell therapies, Tecartus and Breyanzi, to cure highly resistant large B cell lymphoma and mantle cell lymphoma (MCL), respectively [2].

Multiple myeloma is the very often identified hematological malignancy in the USA, accounting for $1 \%$ of all cancers and $10 \%$ of all hematological tumors. [3]. It is occurred by developing malignant plasma cells in the BM, linked with an aberrant elevated level of monoclonal immunoglobins in the patient's blood and urine. Additionally, individuals with MM develop severe osteolytic bone lesions and suffer from immunosuppression, impairing longevity and quality of life [4,5]. Latest developments in potential treatments including PI and IMiD have given rise to a considerable improvement in outcomes for individuals with multiple myeloma (MM) [3, 6-8]. Precision treatment has grown in popularity as a result of the introduction of focused therapy. Several unavoidable side effects remain, such as multidrug resistance, which reduces treatment efficacy [9]. Additionally, several prominent target antigens, like CS1 or CD319 (also referred as CD38 and SLAMF7), are expressed in non-tumor cells, resulting in undesirable off-tumor toxicities [10,11]. As a result, innovative therapeutic options are needed, particularly for patients with high-risk R/R multiple myeloma [12-15]. The process of developing a new drug continues to be lengthy, taking roughly ten to twelve years to deliver an effective medicine or prospective therapeutic molecule from the laboratory to the market [16].

BCMA is considered as the leading target for the treatment against multiple myeloma. At the present, the three most often utilized therapeutic approaches for BCMA are bispecific antibody constructs such as antibody-drug conjugates (ADCs), BiTE® (bispecific T-cell engager), immuno-oncology therapies, and CAR-modified T-cell therapy. CAR T cells mediated B cell maturation antigen treatment has demonstrated clinical effectiveness in multiple myeloma. This review article is an overall outline of all available CART cell-mediated BCMA in myeloma treatment. 


\section{B cell Maturation Antigen (BCMA):}

BCMA is also referred to be CD269 or TNFRSF17 [17,18]. The 2.92-kilobase-long TNFRSF17 gene transcribes it on chromosome 16's short arm (16p13.13). It is composed of three exons and two introns. BCMA is a 184-amino acid peptide. It possesses a type III transmembrane glycoprotein of 20.2-kDa with a conserved six-cysteine motif at the extracellular $\mathrm{N}$ terminus [19-22]. It belongs to the superfamily of tumour necrosis factor receptors (TNFRs) [7]. Human BCMA has four natural splice variants with varying receptor binding affinities, intracellular domain signalling and membrane anchoring capabilities [20,23]. It contains two ligands: APRIL and BAFF, which are primarily produced in a paracrine manner in the bone marrow by osteoclasts, stromal cells, and macrophages [24-27]. It is mainly expressed by mature B lymphocytes, with low nonhematopoietic tissue and hematopoietic stem cells levels. It is indispensable in order to function bone marrow plasma cells which were known to be long lived [28-31]. BCMA, in conjunction with the other two functionally active parts of the TNFR superfamily, BAFF; B cell-activating factor, BAFF-R; B cell-activating factor receptor, and transmembrane activator and calcium modulator and cyclophilin ligand interactor TACI regulates B cell proliferation, maturation, and survival, as well as plasma cell differentiation [32-39]. APRIL is a proliferation-stimulating ligand with a greater affinity for BCMA than BAFF [40] (Figure 1). It binds to TACI [41], while BAFF has a greater affinity for BAFF-R (Figure 1). BCMA is predominantly expressed in plasma blasts and plasmacytoid cells [42]. Additionally, low amount of the substances are detected on memory B cells that are dedicated towards PC development as well as plasmacytoid dendritic cells [43]. With the exception of some parts of the human body including the trachea, the testis and certain segments of the gastrointestinal tract, the BCMA is not detectable in naive B cells,normal non-hematologic tissues or hematopoietic stem cells. [16]. 


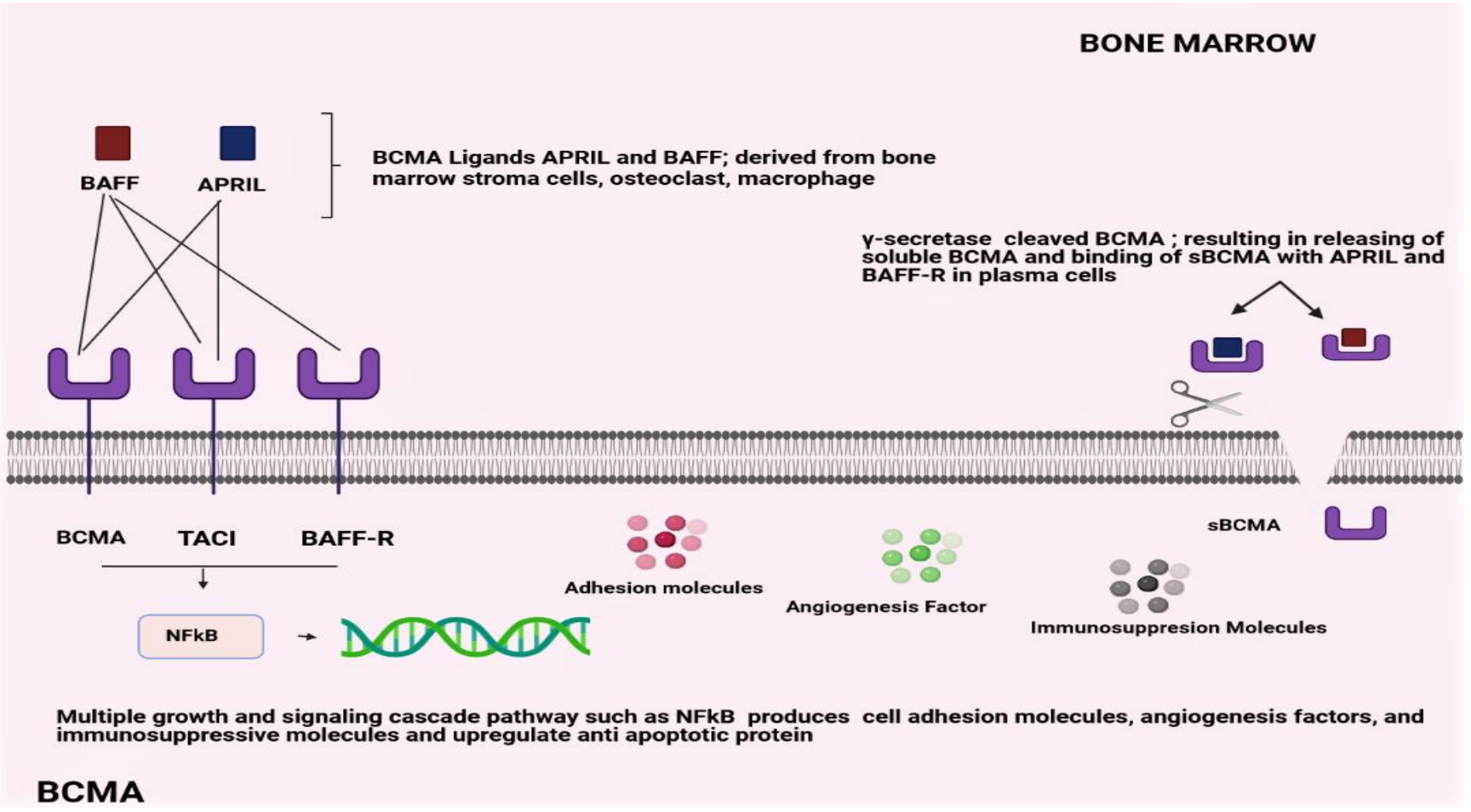

Figure 1: The structural overview of BCMA's binding affinities.

\section{The function and expression of BCMA}

BCMA surface protein, commonly termed as CD269 or TNFRSF17, is initially expressed in late memory B cells and is afterwards frequently observed on plasma cells. [4,5]. BAFF and APRIL, two B-cell activation and expnasion -inducing ligands, bind to BCMA. As a result, multiple myeloma cells activate considerable growth and survival signalling cascades, most notably NF-kB, as well as the PI3K-PKB/Akt and RAS/MAPK signalling pathways [44-47].

APRIL and BAFF serum levels are approximately 5-fold higher in multiple myeloma patients than healthy donors [41]. The more progressed myeloma phase and the elevated concentration of ligands was identified [48]. Multiple myeloma cells have been demonstrated to encourage osteoclasts to release more APRIL, resulting in a reduction of the efficacy of the immune system on BM microenvironment [24,49]. It has been reported that the addition of APRIL-blocking monoclonal antibodies (mAbs) to B cell maturation antigen directed immunotherapies may help alleviate the immunosuppressive BM milieu created by $\mathrm{MM}$ cells, hence increasing antibody-dependent cell-mediated cytotoxicity (ADCC) against multiple myeloma cells. BCMA are mandatory for the maturation and survival of long-lived plasma cells but maybe less crucial for the overall humoral B-cell response $[29,30]$. BCMA is frequently expressed at a wide variety of epitope densities on 
multiple myeloma cells [24] and has been shown to enhance MM development and reduction of immune system activation in the BM microenvironment [50]. Membrane-bound BCMA can be hydrolyzed by $y$-secretase, resulting in the reduction of overall BCMA cell surface expression and the formation of a soluble form (sBCMA) that interferes with the binding of therapeutic compounds to BCMA. [50]. Notably, there has been no evidence of many BCMA expressions in nonhematological regions. BCMA overexpression considerably enhances xenografted multiple myeloma cell proliferation in vivo in mouse models [24]. Additionally, BCMA expression is up-regulated during the pathophysiology and progression of multiple myeloma, from average to monoclonal gammopathy of undetermined significance to smoldering MM to active MM [38]. Up-regulated BCMA levels are related to worse outcomes [31], implying that BCMA may be a valuable indicator of disease activity and prognosis in multiple myeloma. BCMA overexpression activates the NF- $\kappa \beta$ and MAPK pathways in multiple myeloma cells in vitro where APRIL/BAFF activation is not required. [51]. Additionally, there are numerous interactions between the APRIL or BCMA signalling pathway and other pathways. For instance, APRIL promotes the survival and rapid multiplication of myeloma cells by interacting with HSPG which is also known as CD138/syndecan-1 and heparan sulfate proteoglycans [52]. BCMA expression decrease when FGF-R3 and JAK2 are inhibited concurrently [53]. Additionally, an in vitro investigation demonstrates that BCMA co-immunoprecipitants with a master transcription factor (interferon regulatory factor-4; IRF-4), involved in MM cell survival, underlining BCMA's significance in MM oncogenesis [54].

\section{BCMA: A Potential Target in Cancer Treatment}

Given that plasma cells frequently comprise a small subsection of bone marrow cells in multiple malignant myelomas, identifying these cells are essential for accurately characterizing the disease. [55].CD138 is a well-established multiple myeloma biomarker that is highly selective for plasma cells but swiftly fades from the cell surface when samples are delayed or frozen [55].

As a result, additional biomarkers for diagnosing and monitoring multiple myeloma are required. B cell maturation antigen is extremely expressive on malignant PCs isolated from MM patients compared to normal bone marrow mononuclear cells from healthy individuals. Numerous researches have examined its value as a diagnostic, prognostic, and/or predictive marker of clinical outcomes [ 56-61 ]. In contrast to CD138, BCMA is usually observed in multiple myeloma samples that have been delayed or frozen [55]. The volume of membrane-bound BCMA can be quantified using flow cytometry and immunohistochemistry; however, the measurement of BCMA volume can vary between researches due to methodological variances [56,61]. Interestingly, malignant PCs 
express BCMA's mRNA at comparable levels in newly analyzed multiple myeloma and refractory/relapsed multiple myeloma patients, implying that BCMA may be a feasible therapeutic target throughout the MM disease stages [57]. BCMA possesses a soluble form which known as soluble BCMA, formed from the membrane BCMA being shed directly via $y$-secretase activity. The extracellular domain and a portion of the transmembrane region are retained in SBCMA [50].

Soluble BCMA may serve as an identification marker for B cell involvement in autoimmune illnesses including rheumatoid arthritis, multiple sclerosis and systemic lupus erythematosus in humans [50,62]. The serum volume of sBCMA is substantially greater in MM patients than in healthy patients [33].An elevated blood level of soluble BCMA is associated with a more significant disease strain, a less favorable clinical and radiological reaction, and a worse diagnosis[63]. A substantial drop in the volume of soluble BCMA was identified in individuals who responded well to BCMA-targeted immunotherapy, implying that it may be an innovative biomarker to monitor response of multiple myeloma treatment [59].

In contrast to sBCMA, numerous investigations have demonstrated that the amount of BCMA on the cell surface appears not to influence the reaction to BCMA-targeted therapy [64]. It is also feasible that the different volume of BCMA on the cell surface of myeloma patients are simply the product of membrane BCMA shedding differences. An elevated level of soluble BCMA can impair BCMA-targeted therapy by decreasing the overall quantity of BCMA on the cell surface and isolate the circulating ligands or anti-BCMA antibodies, thereby damaging their efficiency of binding to MM cells [65,66]. A y-secretase inhibitor (GSI, LY3039478/JSMD194) was recently reported to lower soluble BCMA concentrations while increasing cell-surface BCMA expression in multiple myeloma cell lines, patient tumour cells, and animal models. This inhibitor dramatically enhanced the recognition of BCMA-specific CAR-T cells in vitro and their anti-tumour activity in vivo. Additionally, preclinical studies have revealed that short-term GSI treatment of MM patients significantly raised the percentage of BCMA+ tumour cells [67].

\section{CAR T cell targeted BCMA therapy}

CAR $\mathrm{T}$ cells are engineered $\mathrm{T}$ cells that express a CAR directed against a specific tumour-associated antigen that, upon contact, activates $\mathrm{T}$ cells in a way independent of human leukocyte antigen [68-71]. These CAR constructs are composed of TAA-targeted scFvs (usually animal or human) coupled to the $\mathrm{CD} 3 \zeta$ intracellular signalling domain via an extracellular spacer and transmembrane region and costimulatory domains (CD28, OX40, 4-1BB etc) [69-71]. 
While the first generation of CARs featured only a CD3 $\zeta$ signalling domain, the second, third, and fourth generations of CARs contained numerous costimulatory domains to increase the likelihood of CAR T-cell proliferation [69,70]. CAR T cell proliferation in vivo has been demonstrated to correlate with clinical efficacy and are routinely examined in preclinical and clinical investigations [59,61 72]. T cells can express CARs by genetic alteration techniques such as CRISPR. CARs are fusion proteins with an antigen detection site on the surface, often $\mathrm{scFv}$ generated from an antibody and a costimulation domain inside the cell. Despite $\mathrm{T}$ cells altered with a $\mathrm{T}$ cell receptor, CAR T cells are not bound by the major histocompatibility complex. [73]. Since the last five years, CAR T cells targeting BCMA therapy have shown revolutionary changes in cancer treatment . In multiple

myeloma, several anti-BCMA CAR T cell therapies have demonstrated impressive clinical activities reaching 90-100\%, developed and under preclinical and/or clinical investigations. CAR T cell-targeted BCMA therapy are classified into Autologous BCMA, Allogenic BCMA, Bispecific , BCMA-CS1 CCAR T-cells, APRIL CAR T cell, BCMA CAR T cell with tEGFR, P BCMA 101, CT053, CAR-NK cells targeting BCMA etc .Engineered CAR T cells release chimeric antigen receptor which can easily bind with BCMA receptor and increase anti tumour activity (Figure 2).

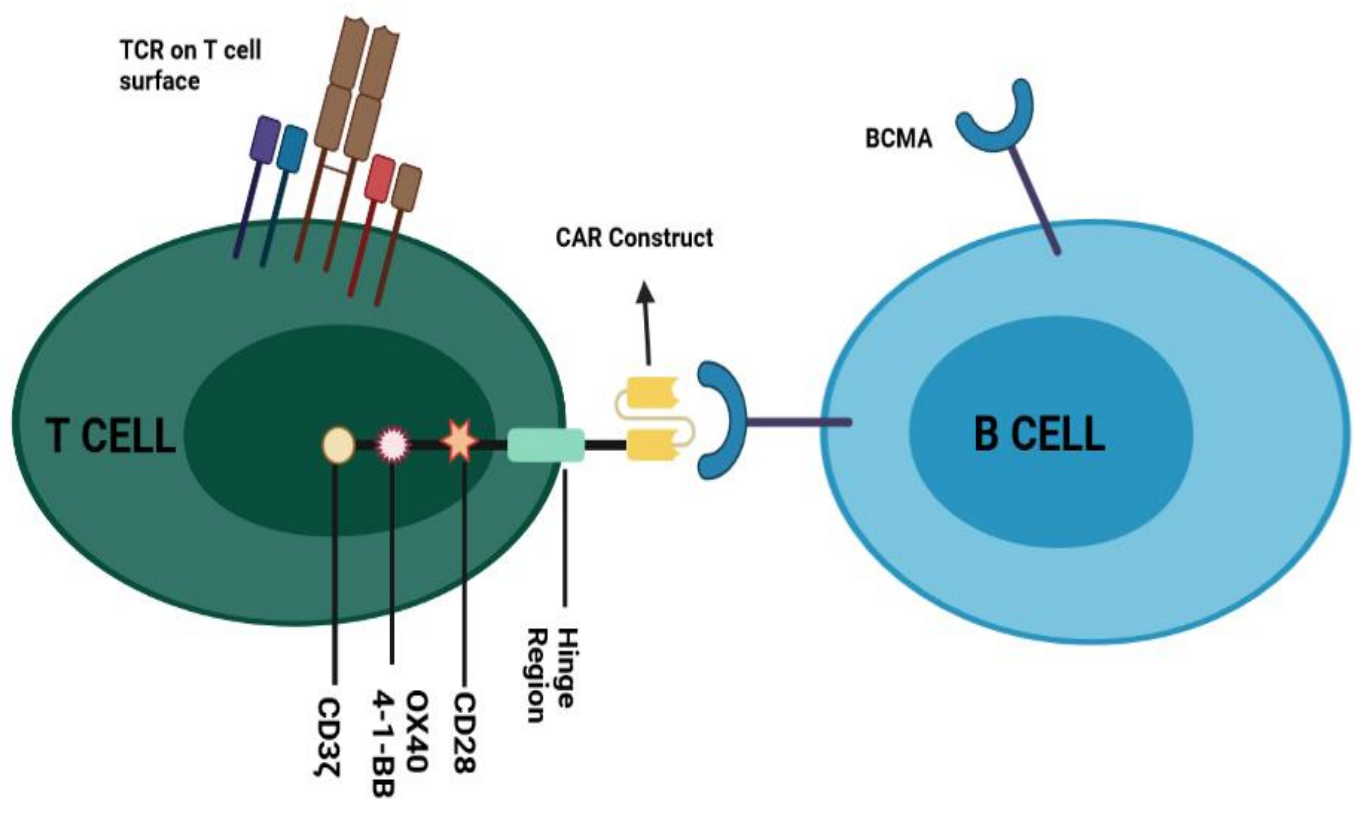

Engineered CAR T cell expressing Chimeric Antigen Receptor to bind with B cell Maturation Antigen on Multiple Myeloma Cell

Figure 2: A schematic overview of engineered CAR T cell binding with BCMA of Multiple Myeloma Cell. 


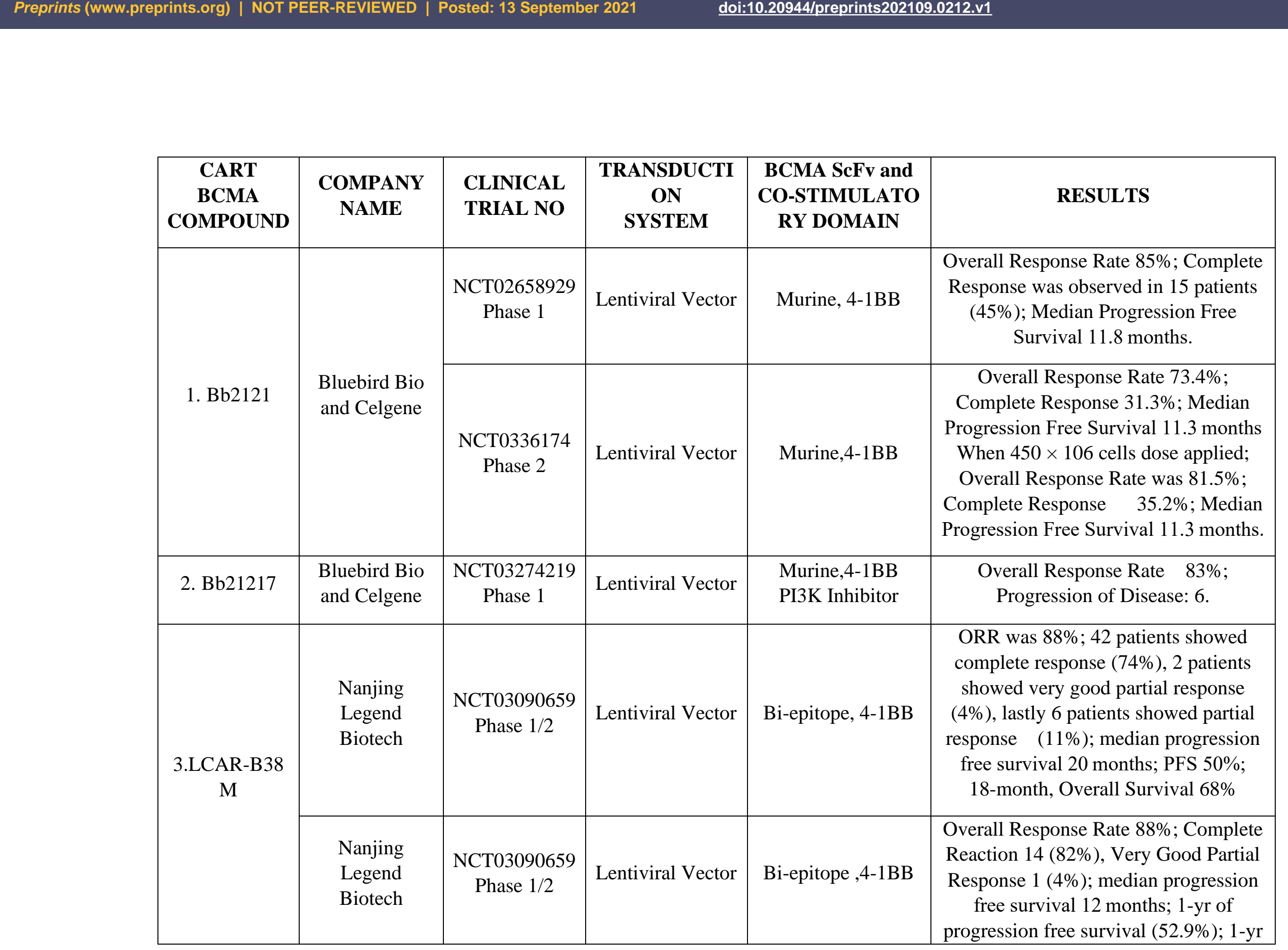




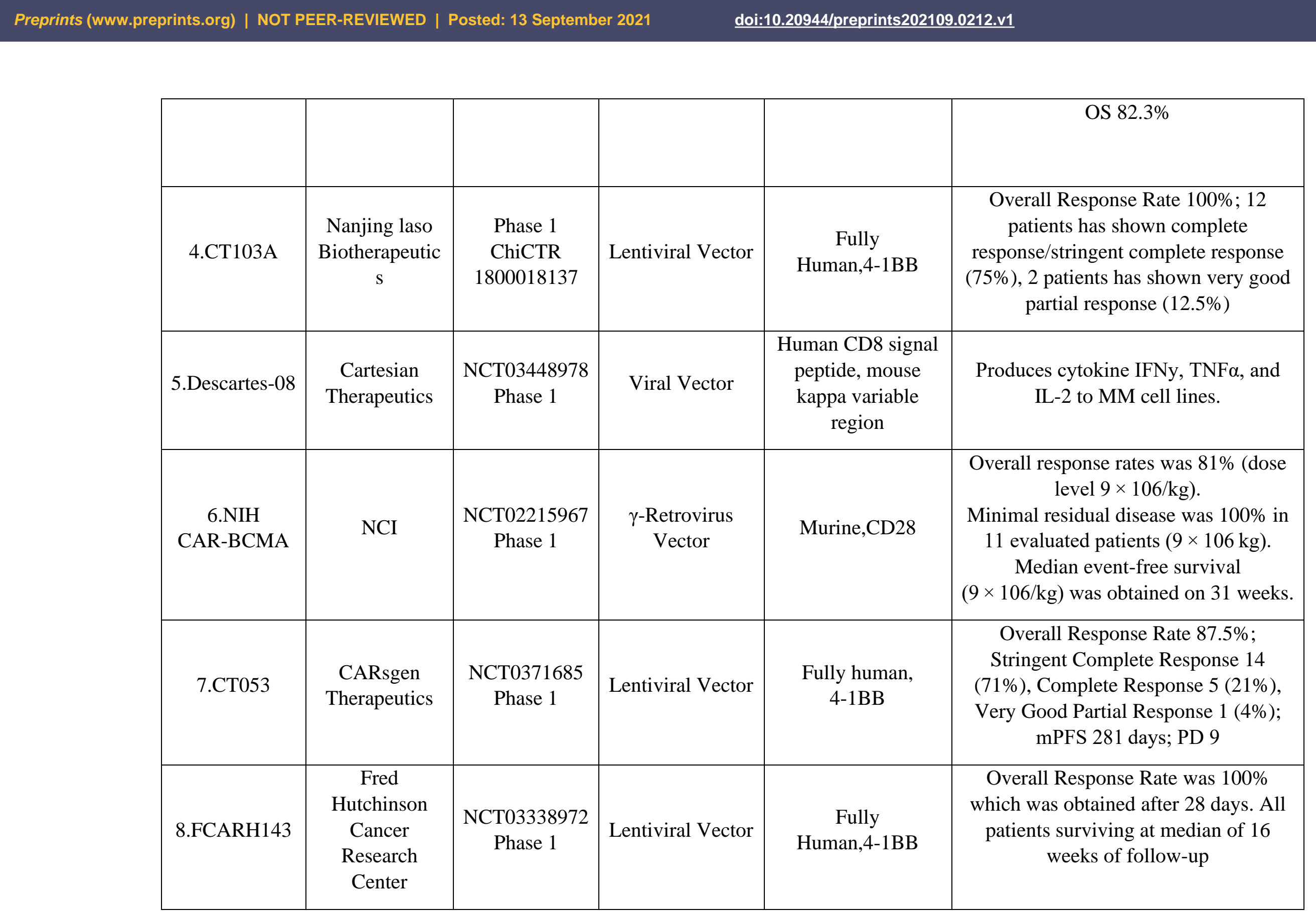




\begin{tabular}{|c|c|c|c|c|c|}
\hline $\begin{array}{c}\text { 15.CART-19/ } \\
\text { BCMA }\end{array}$ & $\begin{array}{c}\text { The First } \\
\text { Affiliated } \\
\text { Hospital of } \\
\text { Soochow } \\
\text { University }\end{array}$ & $\begin{array}{c}\text { NCT03455972 } \\
\text { Phase 1/2 }\end{array}$ & Lentiviral vector & $\begin{array}{c}\text { Fully human/OX40 } \\
\text { and CD28 } \\
\text { costimulatory } \\
\text { domains }\end{array}$ & $\begin{array}{c}\text { Overall Response Rate was 100\% in 9 } \\
\text { patients after the infusion ASCT, and } \\
\text { CAR T-cell . Three patients showed } \\
\text { complete response and six patients } \\
\text { showed very good partial response. }\end{array}$ \\
\hline $\begin{array}{c}\text { 16.BCMA } \\
\text { CAR-T }\end{array}$ & $\begin{array}{c}\text { ShenZhen } \\
\text { Biotechnology } \\
\text { Company, Ltd }\end{array}$ & $\begin{array}{c}\text { NCT03661554 } \\
\text { Phase 1 }\end{array}$ & Lentiviral Vector & $\begin{array}{c}\text { Anti-BCMA scFv, } \\
\text { 4-1BB } \\
\text { costimulatory } \\
\text { domain }\end{array}$ & $\begin{array}{c}\text { ORR was obtained in 28 days among } \\
\text { Overall Response Rate was } 100 \% \text { in 7 } \\
\text { patients after } 10 \text { weeks. 3 patients } \\
\text { showed sCR, 1 showed VGPR, 3 } \\
\text { showed PR. }\end{array}$ \\
\end{tabular}

Table 1: Clinical Trials of CART cell mediated BCMA targeted therapy on multiple myeloma 


\section{Autologous BCMA CAR T cell therapy:}

bb2121

bb2121 are specified as BCMA CAR T cells which are developed by transmitting autologous T cells with a second-generation chimeric antigen receptor. It has a scFv (anti BCMA), a CD3 $\zeta$ activation domain, and a costimulatory molecule of 4-1BB which are included through the lentiviral vector BB2121 [61]. After single-dose administration, bb2121 swiftly and persistently eradicated myeloma cells and concluded in 100 percent survival in a multiple myeloma animal model. A phase 1 clinical trial of bb2121 was done in thirty patients with refractory/relapsed MM who've had at least three prior lines of treatment, including proteasome inhibitors and immunomodulatory drugs or was resistant to both medications, with a data cutoff date of more than six months following the last administration time (NCT02658929) [74]. Overall, 85 percent of patients responded, and 45 percent had a complete or near-complete response, with a median duration of response of 10.9 months. Progression free survival was almost 12 months on average. In sixteen individuals assessed for minimal residual disease negativity, 100 percentage of patients were minimal residual disease negative at 10-4 cells or greater, $94 \%$ at 10-5 cells or greater, and 19\% at 10-6 cells. In comparison, two participants who did not respond to bb2121 were MRD positive one month after infusion. Each of the 33 patients suffered adverse events, with 97 percent suffering at least one grade 3 adverse event. Cytokine reaction sydrome developed in $76 \%$ of individuals, including two with grade three cytokine reaction syndrome. One individual patient sustained grade four neurotoxicity in 11 days after drug administration out of fourteen patients who experienced neurotoxicity. In late 2017, the FDA designated bb2121 as a breakthrough therapy based on early clinical data. Another clinical trial of phase two of bb2121 in individuals with R/R multiple myeloma has been initiated (KarMMa, NCT03361748). Patients with refractory relapsed MM who have had at least three prior lines of treatment, including IMiD, PI, and CD38 $\mathrm{mAb}$, and were resistant to their final treatment are eligible to participate. After lymphodepletion, one dosage of bb2121 is given [74,75]. As of October 16, 2019, One hundred twenty eight individuals had received the therapy (four received $150 \times 106$ total CAR+ cells, seven received $300 \times 106$ total CAR+ cells, and four received 450× 106 whole CAR+ cells). The median number of previous therapies was six. The median duration of follow-up was 11.3 months.Ninety-four patients demonstrated positive reactions. The ORR was 73.4 percent, with 40 (31.3 percent) complete responses, and the median PFS was 8.6 months. Patients who got $450 \times 106$ total CAR+ cells attained an ORR of 81.5 percent, a complete response of $35.2 \%$, and a median PFS of 11.3 months, demonstrating that greater doses may be linked with improved response and results. CAR-T cell up-regulation increases around day 11 and persists for an extended period, as systemic CAR-T cells were identifiable in twenty-nine individuals at six 
months and four patients at twelve months post-administration. Additionally, increased expansion was found when a large dose was administered.

Cytopenia was the most often occurring adverse event (97 percent). One hundred seven patients had cytotoxicity, including seven grade 3 episodes and one death. Twenty-three patients developed neurotoxicity, including four grade 3 episodes [76]. Furthermore, a new phase three trial is recruiting patients with relapsed/refractory multiple myeloma to differentiate the safety and effectiveness of bb2121 to standard three drug dosages such as daratumumab + bortezomib + dexamethasone, ixazomib + lenalidomide + dexamethasone or daratumumab + pomalidomide + dexamethasone.

\section{bb21217}

bb21217 CAR T-cell constructions are an abridged variant of bb2121, for which there are currently in clinical trials [77]. These are cultivated ex vivo; associated with phosphoinositide three kinase inhibitor bb007 to induce a memory-like state in T cells, that is believed to enhance the diligence and effectiveness of CAR T cells. The ORR was 86 percent among seven treated patients, with one achieving a stringent complete response, three with a VGPR, two achieving a PR, and all three evaluable persons testing negative for MRD using next-generation sequencing. Complete response rates of 62.5 percent were found, including one case of grade three cytokine reaction syndrome associated with grade 4 encephalopathy and symptoms of posterior reversible encephalopathy syndrome. Patients with R/R MM who have had three prior therapies, including an IMiD and a PI, or double-resistant to both classes of medicines are now being included in a multicenter phase 1 dose-escalation trial. It is currently recruiting participants for trials (CRB-402, NCT03274219). Only individuals with a BCMA expression level of $\geq 50 \%$ on malignant plasma cells were recruited. There were four planned dosage levels of total CAR+ T cells: $150 \times 106,450 \times 106$, or $800 \times 106$, and 1200× 106 [77]. Twenty-two patients (median age 63) have received bb21217 infusions thus far $(12$ at $150 \times 106,6$ at $300 \times 106$, and 4 at $450 \times 106)$. The median number of previous treatment was seven. Eighteen patients (82\%) had autologous stem cell transplant among which seven had cytogenetic abnormalities. Eighteen individuals were evaluated for early clinical reactions in one month. Six of the fifteen patients who reacted (83 percent) have progressed. Ten out of ten evaluable respondents achieved undetectable MRD status. Six out of eight patients were followed up at six months and other two patients were evaluated at twelve months had detectable CAR+ T cells in peripheral blood. Fifteen individuals $(68 \%)$ acquired a treatable form of cytotoxicity (Five patients was in grade 1, Two patients was in grade 2, One patient was in grade 3). 
Five patients (23\%) developed NTX (One showed grade 1, Two showed grade 2, One showed grade 3, One showed grade 4) all of which were resolved satisfactorily [75]. Moreover, there is currently no indication that bb21217 is more advanced than bb2121 in clinical response durability.

\section{LCAR B38M}

It is a CAR T cell treatment which uses autologous T cells. This CAR T cell treatment is consist of dual BCMA epitope binding which means it can targets two different BCMA epitopes simultaneously. The bi-epitope BCMA-binding compounds have a elevated level of binding affinity for BCMA than earlier BCMA CAR structures, indicating that they are more effective. In the case of LCAR-B38M, 4-1BB serves as the costimulatory domain. Enrolment in the trial was not contingent on the presence of BCMA expression [78]. Stage 1 research of LCAR-B38M in 57 patients with refractory/relapsed multiple myeloma, has been published. All of the patients experienced grade one side effects, with 37 patients experiencing grade 3 adverse events, which included leukopenia, thrombocytopenia, and a rise in aspartate aminotransferase. Among fifty-seven patients, fifty-one had cytokine reaction syndrome, with four patients having grade three cytotoxicity. The ORR was 88 percent, with thirty-nine patients experiencing a complete response, three experiencing a very good partial response, and eight experiencing a partial response. For 36 patients, there was no evidence of minimal residual disease. The average time it took to receive a result was about one month. With an average investigation of 8 months, the median PFS was 15 months, however the median overall survival was not attained within this time period.

Another stage 1 research of LCAR-B38M involved seventeen patients with RRMM [79], similar to the first study. Cytokine reaction syndrome was experienced by ten people, 6 of whom had severe but treatable CRS, and 1 of whom died as a result of a very toxic reaction to the drugs used.

The ORR was 88.2 percent, with 13 stringent complete responses and two partial responses that were extremely good. With a median investigation of 1 year and 52 days, eight patients were still in complete response or very good partial response whereas six patients relapsed after stringent complete response, and one patient developed progression of disease after very good partial response. CAR T-cells were detected in high concentrations in the larger number of cases with sustained responses but were found in low concentrations in six out of seven relapses of progression of disease cases.

A median clinical investigation of almost 2 years shown to be sufficient for six patients to remain progression-free [80]. The median progression free survival for all patients was 1 year, whereas the median progression free survival for MRD negative patients with a complete response was 18 months in this group. The median overall survival rate was not attained, according to the data. A 
phase two clinical trial of this CAR T cells therapy in patients with refractory/relapsed multiple myeloma is still being conducted (NCT03758417).

\section{CT103A}

This unique CAR-T cell therapy, designated CT103A, was manufactured using a lentiviral vector carrying a second-generation chimeric antigen receptor structure with a completely human $\mathrm{scFv}$ from monoclonal antibody, 4-1BB costimulatory, and $\mathrm{CD} 3 \zeta$ activation domains. In China, it is undergoing a stage 1 clinical trial in a single-center environment (ChiCTR1800018137). Approximately sixteen patients with refractory/relapsed MM who were resistant to a median of four prior lines were enrolled as of August 1, 2019. All patients were included in a dose-escalation experiment. They received CT103A (four doses at 1, 3, 6, and $8 \times 106 / \mathrm{kg}$ ) following a CTX or FAMP conditioning treatment for a median of 195 days following drug administration. The research demonstrated an outstanding result with an overall response rate of 100 percent, with twelve patients achieving a complete response/stringent complete response and two patients achieving a VGPR, with six patients obtaining a CR/sCR within two weeks of drug administration. MRD -negative status was achieved in all fifteen of the individuals who were evaluated. The number of CT103A cells in circulation peaked two weeks after the administration and remained identifiable in twelve out of sixteen individuals six months later. Sixteen patients experienced a lower grade of cytokine response syndrome, with one grade four event occurring at a dose level of 6 $\times 106 / \mathrm{kg}$, which was classified as dose-limiting toxicity. There was no evidence of neurotoxic effects $[81,82]$. On day 19 , one patient died due to lung infection after receiving the infusion. Despite this promising early outcome, additional research is needed to determine the shielding and effectiveness of this BCMA-targeted CT103A.

\section{Descartes-08}

Descartes-08 is known as autologous CD8+ $\mathrm{T}$ lymphocytes that have been treated with an anti-BCMA CAR produced from mRNA [83]. It produces cytokine IFNy, TNFa, and IL-2, which were used to kill multiple myeloma cell lines, trigger cytotoxic degranulation and also helps to kill primary MM cells from individuals with newly discovered MM and refractory/relapsed MM .It also decreases MM in a rodent model of diffuse human multiple myeloma. Descartes-08 has a time limit inactivity, which may reduce the risk of severe central nervous system toxicities in some cases. Descartes-08 is now being studied in stage one clinical trial (NCT03448978). 


\section{Allogenic BCMA CAR T cells:}

BCMA 1 R2 are anti--BCMA allogeneic CAR T cells which are taken from healthy individuals to overcome the lag in treatment caused by the autologous CAR T's cell collection and manufacturing [84]. To decrease the potential of GVHD, the genetic alternation technique TALEN was used. BCMA 1-R2 CAR T cells were made through TALEN by disrupting the CD52 gene. These cells were resistant to lymphodepletion treatment with alemtuzumab when exposed to the drug. Moreover, it is engineered to contain an intra-CAR rituximab binding domain that served as an off switch, enabling the eradication of these CAR T-cells by rituximab. BCMA 1-R2 CAR T cells have illustrated anti-tumour efficiency in MM mouse models when treated with human cytokine interleukin 7 and 15.

\section{Bi-specific CAR T cells:}

Engineered chimeric antigen receptor $\mathrm{T}$ cells that are multiantigen-targeted and bi-specific are currently in the research and development stage $[85,86]$. The improvised bispecific CAR-T cells can target B cell maturation antigen plus other tumor-specific antigen such as CD38 or CD19 has recently been completed in order to increase therapeutic effectiveness by minimizing the likelihood of relapse due to antigen evasion.

\section{CD-19 CAR T Cells}

In recent years, researchers in China have developed a bispecific CAR-T product that contains both the CD19 and BCMA. It is effective against BCMA and CD19. In order to produce it, BCMA and $\mathrm{CD} 19 \mathrm{scFv}$, as well as $\mathrm{CD} 3 \zeta$, a CD8 hinge, transmembrane domain, costimulatory domain are linked together [87]. The BCMA-CD19 bispecific CAR-T cell was created in a single day using the FasT CAR-T platform.

When used in amalgamation with CD19, this cells efficiently eradicated tumours in MM xenograft mice, disrupted CD19+ and/or BCMA+ multiple myeloma cell lines, and was found to have more cytokine reaction syndrome than single CAR-T treatment. A median check up of two months and eight days revealed that BCMA-CD19 bispecific CAR-T was effective on all five multiple myeloma patients, with one achieving a CR (complete response), three achieving a VGPR, and one attaining a PR. Three patients had a grade one cytokine reaction syndrome, and no severe adverse events was seen in any of the patients. A phase one/two clinical study of FasT BCMA-CD19 CAR-T is underway [87]. 


\section{CD38 BCMA CAR T cells}

Among the lymphoid cell populations, PCs and other lymphoid cell types express the glycoprotein known as CD38. Due to CD 38's elevated homogeneous expression on multiple myeloma cells, it is a suitable target for innovative therapeutic techniques, such as monoclonal antibodies (mAbs) (daratumumab and isatuximab) $[88,89,90]$. A bispecific CAR T cell that kills both CD38 and BCMA is known as a BCMA-CD38 bispecific CART [91]. It consists of CAR T cells that incorporate the scFv (anti-CD38 and anti-BCMA ) in tandem, as well as CD3 $\zeta$ domains and 4-1BB costimulatory domain. In China, a primary level of one dose-escalation trial has been initiated (ChiCTR1800018143).

Administration of BM38 CAR-T cells were infused to 16 individuals with refractory/relapsed MM who had undergone at least two prior routine treatment as of July 31, 2019. The dose of this CAR-T cells ranged from 0.5 to $2.0,3.0$, and $4.0 \times 106$ cells $/ \mathrm{kg}$. The average amount of time spent on following up was nine months. Fourteen patients achieved an ORR of 100\%, with eight achieving a $\mathrm{sCR}$, two achieving a very good partial response, and four achieving a partial response. Fourteen patients achieved negative status in minimum residual disease, and all extra-medullary lesions were removed in all five patients. The stringent complete response took an average of more than 51 weeks to complete. At the time of the data collection date, five of the eight stringent complete response patients had retained stringent complete response status, two had transitioned to VGPR, and one had transformed to the PR. It was shown that the progression-free survival rate was $75 \%$ after nine months. The dose of $4.0 \times 106$ cells $/ \mathrm{kg}$ was chosen as the starting point for a future dose-expansion investigation. Ten individuals were diagnosed with grade 1-2 cytokine reaction syndrome, with four patients suffering from reversible grade 3 cytokine reaction syndrome. All haematological toxicities were alleviated within the first month of the infusion's administration. There have been no reports of neurotoxicity, dose-limiting toxicity, or fatalities [92].

\section{APRIL and TriPRIL CAR T cell}

APRIL-CAR T-cells are a third-generation CAR that target tumors by using a shortened version of the single form of APRIL protein as the tumour-targeting domain. It identifies both the TACI and the BCMA antigens on multiple myeloma cells [92] . In myeloma cells, April CAR T-cells were able to induce considerable cytolytic activity even at very insignificant level of antigen concentrations.

In an intramedullary murine myeloma model, the eradication of MM cells was also seen. April CAR T-cells eliminated both BCMA+TACI+ and BCMA-TACI+ cells in mice models of tumour 
escape, whereas BCMA-CAR T-cells alone concluded in the development of BCMA-negative tumours. Because of this, in contrast to single-antigen targeting of TACI and BCMA, April CAR's double-antigen targeting of BCMA and TACI permits for more prolonged multiple myeloma suppression in patients with multiple myeloma who exhibit both antigens. While physiological levels of soluble APRIL or TACI had no effect on ACAR T-cell tumour killing, the greatest concentration of soluble BCMA $(1000 \mathrm{mg} / \mathrm{ml})$ had the opposite effect. APRIL CART-cells (NCT03287804) is now being experimented in phase 1/2 clinical research.

Three truncated APRIL monomers are combined to produce a multimeric APRIL binding domain, which retains APRIL's natural trimeric conformation [81]. Additionally, it is effective against multiple myeloma cell lines and mice xenograft models that are positive for BCMA and negative for BCMA. It is also effective against original myeloma cells obtained from MM patients. TriPRIL CAR T cells can eliminate BCMA+ MM cells, and also can remove BCMA-TACI+ from MM cells. It also outperformed monomeric APRIL CARTs in terms of affinity, T cell polyfunctionality and long-term proliferative capacity. TriPRIL CARTs are properly constructed, containing human sequences, and it has the potential to address antigen escape from monospecific target therapy.

\section{BCMA-CS1 cCAR T-cells}

BCMA-CS1 cCAR T-cells contain a fully functional BCMA CAR connected to a fully functional CS1 CAR by a self-cleaving P2A peptide that express both BCMA and CS1 CAR molecules on the T cell surface [93]. Elotuzumab directed against CS1 has been successfully utilized to treat multiple myeloma, and CS1-CAR therapy has shown promising efficacy in preclinical investigations for multiple myeloma [94,95]. It exhibits potent, consistent, and direct cytotoxicity against either CS1or BCMA myeloma cells as a target antigen. BC1cCAR $\mathrm{T}$ cells were found to be more cytotoxic against multiple myeloma communities in animal models when compared with CAR T cells that were only expressed once.

\section{BCMA CAR-T cells with tEGFR}

A company named Hrain Biotechnology in China, has created a second-generation retrovirus-mediated anti-BCMA CAR-T cell that comprises a completely human scFv, CD3 $\zeta$ activation domain, costimulatory domain of $4-1 \mathrm{BB}$ and the tEGFR safety system to facilitate monitoring of BCMA-targeting CAR-T cells. A stage one clinical trial has been initiated to assess the safety and effectiveness of this BCMA CAR-T cell product in the treatment of 
refractory/relapsed multiple myeloma (NCT03093168). This trial involved patients who were unsuccessful in two prior treatment regimens and had plasma cells expressing more than 5\% BCMA. Following normal CTX or FAMP lymphodepletion, a dose of $9 \times 106$ CAR+ cells $/ \mathrm{kg}$ CAR-T cells was delivered.

Forty-four patients had an ORR of 79.6 percent, including two sCR, sixteen CR, eight VGPR, and eight PR, and 16 patients had attained MRD-negative status as of March 1, 2019. The median PFS was 15 months at the data cutoff.

The 24-month PFS rate was 49.16 percent, and the overall survival rate was 53.95 percent, respectively. Ten patients had grade 1-2 cytokine reaction syndrome, and three patients had tolerable grade 3 cytokine reaction syndrome occurrences. Thus far, the trial has lasted more than 26 months [96].

\section{MCARH171}

A new human-derived chimeric antigen receptor T cell treatment named MCARH171 accompanied by a shortened EGFR safety mechanism is now being explored in a stage 1 dose-escalation study [97]. Among eleven patients, five have received a high dose level $\geq 450 \times 106$ cells which obtained an objective response. The overall response rate was 64 percent. The responses lasted between 17 days to 235 days. Three of the five patients who received a high dose maintained a longer response about six months; another two patients maintained a response till 7.5 to 10 months. Cytokine reaction syndrome of grades 1 to 2 occurred among $40 \%$ and $20 \%$ of patients. NTX was observed in one patient.

\section{FCARH143}

It is a completely human derived CAR T-cell treatment directed against BCMA. FCARH143 is produced with same quantity of CD4+ to CD8+ CAR $\mathrm{T}$ cells for administration.It expresses a shortened, nonfunctional human EGF receptor to help in the identification of transduced $\mathrm{T}$ cells [98]. At 28 days , FCARH143 therapy was linked with a 100 percent overall response rate in six patients, and all six patients exhibited no indentifiable aberrant BM plasma cells by flow cytometry or immunohistochemistry. At an average range of sixteen weeks of follow-up, all individuals were alive. Among all the patients ; $86 \%$ of them has shown cytotoxicity of grade 2 or below, and no NTX or neurotoxicity was observed. 


\section{JCARH125}

Another fully human-derived CAR T-cell therapy that contains a costimulatory domain of 4-1BB. It has been studied in people with R/R MM in a multicenter clinical trial of level one and two [88]. The ORR was about $82 \%$ in forty four patients who were treated with a dose range of 50, 150, or $450 \times 106$ cells. Among 44 patients,48\% have achieved a VGPR or even greater. Improved responses were observed in some patients. Six out of nine patients have shown minimal residual disease negative by NGS after 29 days of drug administration. There was $\leq$ one tumour cell per 105 normal cells. Eighty percent of patients have shown cytokine reaction syndrome, and $9 \%$ have shown neurotoxicity.

\section{CART-BCMA}

An open-label phase 1 study was performed with CART-BCMA therapy which is a chimeric antigen receptor $\mathrm{T}$ cell treatment derived from a completely human $\mathrm{scFv}$ with a costimulatory domain of 4-1BB [100]. Twenty-five patients were treated in three dosage groups with varying CART-BCMA doses and/or cyclophosphamide coadministration. The overall response rate was fourty four percent in all 25 treated patients and fifty five percent in those who received the highest dosage level of CART-BCMA cells (dose level $1-5 \times 108$ ). The average response length was almost four months and five days. Three patients were progression-free at the time of data collection, with a median overall survival of 502 days among all treated patients. Despite the trial drug's efficacy, 96 percent of patients had adverse effects of grade 3 or more. Cytokine reaction syndrome was detected in $88 \%$ of patients,among which thirty two percentage of patients has shown neurotoxicity (including three cases of grade 3-4 encephalopathy).

\section{NIH CAR-BCMA}

A clinical trial of level one of dose-escalation trial using NIH CAR-BCMA was conducted in individuals with detectable multiple myeloma and uniform BCMA expression on PCs [60,61]. The ORR rate was 81 percent in sixteen patients treated with dosages level of $9 \times 106$ cells $/ \mathrm{kg}$ or more, and all eleven analyzed patients had minimal residual disease negative status two months following NIH CAR-BCMA drug administration, as determined by BM flow cytometry. The responses lasted between two and fifty-two weeks, and six of the eleven individuals who tested negative for minimal residual disease had a continuing reaction of drug till the final follow-up prior to publication. At lower dosages, treatment-related toxicity was average (no grade $\geq 3 \mathrm{CRS}$ ). Nonetheless, cytokine response syndrome damage was considerable when the dose levels were high $(9 \times 106$ cells $/ \mathrm{kg})$, 
particularly in patients with a huge tumor burden.

\section{KITE-585}

It is second generation CAR T cell product which is produced by using lentiviral vector and it has a completely human derived scFv (anti-BCMA), a CD28 co-stimulatory domain , and a CD3 activation domain. It exhibits effective in prelinical studies against multiple myeloma cell lines even in the presence of sBCMA. It also exterminated xenografted multiple myeloma tumours in murine model [101,102]. A phase one open-label, clinical trial in human was proposed (NCT03318861) to investigate the shielding and feasibility of KITE-585 in patients with refractory/relapsed multiple myeloma [103]. However, this device's development was eventually terminated.

\section{P ВCMA-101}

It is an unique second-generation CAR-T cell therapy composed entirely of human anti-BCMA CentyrinTM co-stimulatory motifs, a CD3 activation domain and a 4-1BB co-stimulatory motif. P-BCMA-101 is unique among all CAR-T lymphocyte products that it is generated using the piggyBacTM (PB) DNA Modification System rather than by a viral vector [104]. Due to the absence of viral transfection, the product may be more cost-effective. Additionally, it comprises a refined population of CAR+ cells that exhibits a significant proportion of the favourable stem cell memory $\mathrm{T}$ phenotype (TSCM). Studies indicated that one dose of P-BCMA-101 was highly effective in decreasing tumour burden and avoiding recurrence in a variety of xenograft models [105]. The stage one dose-escalation trial (NCT03288493) enrolled twelve patients with heavily pretreated multiple myeloma who had previously received a proteasome inhibitors and immuno-modulatory drugs or were double-refractory [106-110]. After conditioning with CTX and FAMP, these patients received single dosage of P-BCMA-101 therapy from $0.75 \times 106$ to $15 \times 106$ cells/kg. Within two weeks, the ORR was 83 percent, among which one showed sCR, one showed VGPR, and three patients showed PR, which was attained in the six patients who got a greater dosage of treatment. The rate of response had no correlation with the amount of BCMA expressed. . The cell level of P-BCMA-101 peaked after 2-3 weeks and remained detectable up to 3 months beyond the data cutoff date. The most commonly occurring severe adverse events were cytopenia and febrile neutropenia.. Noteworthy, there was a low rate of cytotoxicity and neurotoxicity. There was only one incidence of cytokine reaction syndrome of highest grade 2. As a result, this new CAR-T agent may have a higher therapeutic index [111]. PRIME- NCT03288493;A major phase 2 trial has been planned using the results from phase 1 . The study will enroll 100 people with 
refractory/relapsed multiple myeloma who undergone at least three lines of treatment before, including a PI, an IMiD, and CD38 targeted therapy. There is no requirement for a minimum level of BCMA expression. Notably, patients who have previously received BCMA-targeted agents or CAR $T$ cell therapy were also eligible. After a standard three-day CTX/FAMP conditioning regimen, a single dose of P-BCMA-101 CAR-T cells 6-15 106 cells/kg will be given intravenously. Unlike other CAR-T treatments, P-BCMA-101 does not require hospitalization and may be administered in an outpatient environment, based on its phase 1 safety profile [112].

\section{CT053}

CT053 is another CAR-T cell immunotherapy that is being studied in China at the moment. It is a second-generation CAR that contains an entirely human scFv (anti-BCMA) that is considerably less immunogenic, a 4-1BB co-stimulatory motif, and a CD3 activation domain. CT053 is being evaluated in a number of phase one clinical trial in China such as NCT03716856, NCT03302403, NCT03380039, and NCT03975907, all of which enrolled patients with refractory/relapsed MM who were unsuccessful to two prior regimens (on average 4.5). Patients were provided with one cycle of CT053 CAR-BCMA following FAMP/CTX conditioning. As of June 30, 2019, 24 suitable patients had been enrolled (median age 60). Except for three patients who received 0.5 $\times 108,1 \times 108$, and $1.8 \times 108$ cells, the majority accepted a single dose of $1.5 \times 108$ total CAR-T cells The ORR was $87.5 \%$, including fourteen sCR, five CR, one VGPR, and one PR. Seventeen out of the twenty patients attained minimal residual disease-negative status. At the lowest dose of $0.5 \times$ 108, effectiveness of the drug was shown in a patient who sustained a very excellent partial response for $378+$ days and achieved complete response (CR) on day 437, followed by a stringent response on day 502. The mDOF was determined to be 333 days. Thirteen patients maintained a complete or stringent complete response. Nine patients have progressed thus far, with a median progression-free survival of 281 days, three of them died prior to the data cutoff date. Persistence of T cells lasted a median of 172 days and a maximum of 341 days. Hematologic toxicity continued to be the most often reported serious adverse reaction to treatment. Fifteen out of twenty-four patients experienced cytokine response syndrome, which was all minor and resolved within two to eight days. Three people had neurotoxicity identified ( 2 in grade 1, 1 in grade 3 reversible). No dose-limiting toxicity was detected at the time of study [113,114]. Another multicenter phase $1 \mathrm{~b}$ clinical trial of NCT03915184, has begun enrolling patients in the United States of America to assess the safeness and effectiveness of CT053 in individuals with refractory / relapsed multiple myeloma. 


\section{NK BCMA CART therapy}

Engineered Natural Killer cells has been detected as a possible new therapy for cancer treatment in recent years. Natural Killer cells are a kind of innate immune cell. Invariant Natural killer T cells express a single form of T cell receptor and they do not cause GVHD or graft-verses-host-disease. BCMA-iNKT-CAR has shown greater efficacy against multiple myeloma in both cell lines and a mouse model of multiple myeloma. As iNKT generates interleukin 7R, and a long-acting IL-7 known as NT-I7, it improves the antitumor effectiveness of BCMA-iNKT-CAR and prolongs the iNKT-CAR cell survival in vivo. Numerous preclinical studies in multiple myeloma have been done using CAR-Natural Killer cells. Increased cytotoxicity against CD138-positive cells was seen in CAR-NK-92MI cells treated with anti-CD138 scFv [115]. CAR-NK 92 cells directed against SLAMF7 demonstrated enhanced cytolysis in vitro, as well as antitumor effectiveness and prolonged animal life in mouse tumor models [116]. In May 2019, a phase one study of BCMA-specific CAR-NK 92 cell product included 20 patients with R/R MM aged 18 to 80 years in China (NCT03940833). The trial is still underway, and there has been no interim report issued. 


\section{Conclusion and Future Perspective:}

Since its discovery in 1992, BCMA has been a promising target for immunotherapy in multiple myeloma.

Numerous B cell maturation antigen-targeting medicines, including bispecific antibody complexes, ADCs, and CAR T-cell therapies, have demonstrated antimyeloma efficacy in patients with refractory/relapsed multiple myeloma and it may also help to label a substantial unmet need for therapeutics in patients with multiple myeloma [117,119]. CAR T immunotherapy first shown clinical efficacy in a number of phase one trials, with substantial response rates reported in patients who previously had intensive pretreatment for RRMM. Clinical.gov reports that 26 clinical studies are actively recruiting participants for CART cell-mediated BCMA treatment. CAR-T therapy has been demonstrated efficacy in treating extramedullary plasma cell dyscrasia [74,120,121]. Nonetheless, autologous BCMA CAR-T cells take at least two to four weeks to generate and are only available through a limited number of specialist medical institutions, limiting their utilization in patients with rapid disease progression. It can be challenging to produce sufficient autologous BCMA CAR-T cells in older patients ( $\geq 75$ years old) and individuals who have had extensive pretreatment $[47,122]$. The high rate of cytokine syndrome reactions and neurotoxicity, and also the grade $\geq 3$ hematologic adverse events associated with pre-conditioning lymphodepletion, are significant concerns, despite the fact that BCMA CAR-T cells were successfully used in the treatment of patients with refractory/relapsed multiple myeloma [60].

To mitigate the adverse effects of conditioning chemotherapy, viable options include employing chemotherapy without toxicity, treating patients early in the illness cycle with a low tumor load, and providing increased supportive care are essential [123]. Numerous inflammatory cytokines such as interleukin 7 have been investigated, and predictive models for severe cytokine releasing syndrome have been created [123,124]. Cytokine-targeted treatment with tocilizumab, an anti-IL6 receptor inhibitor, may be utilized to relieve CRS symptoms [124,125]. Other strategies for minimizing side effects include modifying the CAR structure, for example, by incorporating suicide genes into modified T cells [126-128], co-expressing an inhibitory chimeric antigen receptor on engineered T cells to inhibit off-target immune responses [129], or controlling CARs with a small molecule system [130,131]. Cost and time effective and accessible CAR T cell therapies are being developed, including allogeneic CAR T cells to treat multiple myeloma in patients. 


\section{Reference:}

1.Maude, S. L., Frey, N., Shaw, P. A., Aplenc, R., Barrett, D. M., Bunin, N. J., ... \& Grupp, S. A. (2014). Chimeric antigen receptor $\mathrm{T}$ cells for sustained remissions in leukemia. New England Journal of Medicine, 371(16), 1507-1517.

2.Quazi, S. (2021). Elucidation of CRISPR-Cas9 Application in Novel Cellular Immunotherapy.

3.Bray, F., Ferlay, J., Soerjomataram, I., Siegel, R. L., Torre, L. A., \& Jemal, A. (2018). Global cancer statistics 2018: GLOBOCAN estimates of incidence and mortality worldwide for 36 cancers in 185 countries. CA: a cancer journal for clinicians, 68(6), 394-424.

4.Robert, K., Morie, G., Thomas, W., John, A. L., Martha, Q. L., Angela, D., \& Rafael, F. (2003). Review of 1027 patients with newly diagnosed multiple myeloma. In Mayo Clin Proc (Vol. 78, No. 1, pp. 21-33).

5.Palumbo, A., \& Anderson, K. (2011). New England Journal of Medicine. NEJM, 364(11)), 1046-1060.

6.Raza, S., A Safyan, R., \& Lentzsch, S. (2017). Immunomodulatory drugs (IMiDs) in multiple myeloma. Current cancer drug targets, 17(9), 846-857.

7.Chehab, S., Panjic, E. H., Gleason, C., Lonial, S., \& Nooka, A. K. (2018). Daratumumab and its use in the treatment of relapsed and/or refractory multiple myeloma. Future Oncology, 14(30), 3111-3121.

8.Le Ray, E., Jagannath, S., \& Palumbo, A. (2016). Advances in targeted therapy for the treatment of patients with relapsed/refractory multiple myeloma. Expert review of hematology, 9(1), 91-105.

9.Gavas, S., Quazi, S., \& Karpiński, T. (2021). Nanoparticles for Cancer Therapy: Current Progress and Challenges.

10.Bazarbachi, A. H., Al Hamed, R., Malard, F., Harousseau, J. L., \& Mohty, M. (2019). Relapsed refractory multiple myeloma: a comprehensive overview. Leukemia, 33(10), 2343-2357. 
11.Liu, D. (2019). Cancer biomarkers for targeted therapy.

12.Liu, D. (2019). CAR-T "the living drugs", immune checkpoint inhibitors, and precision medicine: a new era of cancer therapy.

13.Wu, C., Zhang, L., Brockman, Q. R., Zhan, F., \& Chen, L. (2019). Chimeric antigen receptor T cell therapies for multiple myeloma. Journal of hematology \& oncology, 12(1), 1-12.

14.Lin, Q., Zhao, J., Song, Y., \& Liu, D. (2019). Recent updates on CAR T clinical trials for multiple myeloma. Molecular cancer, 18(1), 1-11.

15.Avigan, D., \& Rosenblatt, J. (2014). Current treatment for multiple myeloma. N Engl J Med, 371(10), 961-2.

16.Quazi, S. (2021). Role of artificial intelligence and machine learning in bioinformatics: Drug discovery and drug repurposing.

17.Madry, C., Laabi, Y., Callebaut, I., Roussel, J., Hatzoglou, A., Le Coniat, M., ... \& Tsapis, A. (1998). The characterization of murine BCMA gene defines it as a new member of the tumor necrosis factor receptor superfamily. International immunology, 10(11), 1693-1702.

18.Sanchez, E., Li, M., Kitto, A., Li, J., Wang, C. S., Kirk, D. T., .. \& Berenson, J. R. (2012). Serum B-cell maturation antigen is elevated in multiple myeloma and correlates with disease status and survival. British journal of haematology, 158(6), 727-738.

19.Kozlow, E. J., Wilson, G. L., Fox, C. H., \& Kehrl, J. H. (1993). Subtractive cDNA cloning of a novel member of the Ig gene superfamily expressed at high levels in activated B lymphocytes.

20.Laabi, Y., Gras, M. P., Brouet, J. C., Berger, R., Larsen, C. J., \& Tsapis, A. (1994). The BCMA gene, preferentially expressed during B lymphoid maturation, is bidirectionally transcribed. Nucleic acids research, 22(7), 1147-1154.

21.Laabi Y, Gras MP, Carbonnel F, Brouet JC, Berger R, Larsen CJ, Tsapis A. A new gene, BCM, 
on chromosome 16 is fused to the interleukin 2 gene by a $t(4 ; 16)(q 26 ; p 13)$ translocation in a malignant T cell lymphoma. EMBO J. 1992;11(11):3897-904.

22.Zhou, L. J., Schwarting, R., Smith, H. M., \& Tedder, T. F. (1992). A novel cell-surface molecule expressed by human interdigitating reticulum cells, Langerhans cells, and activated lymphocytes is a new member of the Ig superfamily. The Journal of Immunology, 149(2), 735-742.

23.Smirnova, A. S., Andrade-Oliveira, V., \& Gerbase-DeLima, M. (2008). Identification of new splice variants of the genes BAFF and BCMA. Molecular immunology, 45(4), 1179-1183.

24.Tai, Y. T., Acharya, C., An, G., Moschetta, M., Zhong, M. Y., Feng, X., ... \& Anderson, K. C. (2016). APRIL and BCMA promote human multiple myeloma growth and immunosuppression in the bone marrow microenvironment. Blood, The Journal of the American Society of Hematology, 127(25), 3225-3236

25.Moreaux, J., Legouffe, E., Jourdan, E., Quittet, P., Rème, T., Lugagne, C., ... \& Tarte, K. (2004). BAFF and APRIL protect myeloma cells from apoptosis induced by interleukin 6 deprivation and dexamethasone. Blood, 103(8), 3148-3157.

26.Tai, Y. T., Li, X. F., Breitkreutz, I., Song, W., Neri, P., Catley, L., ... \& Anderson, K. C. (2006). Role of B-cell-activating factor in adhesion and growth of human multiple myeloma cells in the bone marrow microenvironment. Cancer research, 66(13), 6675-6682.

27.Mulazzani, M., Huber, M., Borchard, S., Langer, S., Angele, B., Schuh, E., ... \& von Baumgarten, L. (2019). APRIL and BAFF: novel biomarkers for central nervous system lymphoma. Journal of hematology \& oncology, 12(1), 1-14.

28.Novak, A. J., Darce, J. R., Arendt, B. K., Harder, B., Henderson, K., Kindsvogel, W., ... \& Jelinek, D. F. (2004). Expression of BCMA, TACI, and BAFF-R in multiple myeloma: a mechanism for growth and survival. Blood, 103(2), 689-694.

29.O'Connor, B. P., Raman, V. S., Erickson, L. D., Cook, W. J., Weaver, L. K., Ahonen, C., ... \& Noelle, R. J. (2004). BCMA is essential for the survival of long-lived bone marrow plasma cells. Journal of Experimental Medicine, 199(1), 91-98. 
30.Xu, S., \& Lam, K. P. (2001). B-cell maturation protein, which binds the tumor necrosis factor family members BAFF and APRIL, is dispensable for humoral immune responses. Molecular and Cellular Biology, 21(12), 4067-4074.

31.Carpenter, R. O., Evbuomwan, M. O., Pittaluga, S., Rose, J. J., Raffeld, M., Yang, S., ... \& Kochenderfer, J. N. (2013). B-cell maturation antigen is a promising target for adoptive T-cell therapy of multiple myeloma. Clinical cancer research, 19(8), 2048-2060.

32.Coquery, C. M., \& Erickson, L. D. (2012). Regulatory roles of the tumor necrosis factor receptor BCMA. Critical Reviews ${ }^{\mathrm{TM}}$ in Immunology, 32(4).

33.Marsters, S. A., Yan, M., Pitti, R. M., Haas, P. E., Dixit, V. M., \& Ashkenazi, A. (2000). Interaction of the TNF homologues BLyS and APRIL with the TNF receptor homologues BCMA and TACI. Current Biology, 10(13), 785-788.

34.Gross, J. A., Dillon, S. R., Mudri, S., Johnston, J., Littau, A., Roque, R., ... \& Clegg, C. H. (2001). TACI-Ig neutralizes molecules critical for B cell development and autoimmune disease: impaired B cell maturation in mice lacking BLyS. Immunity, 15(2), 289-302.

35.Thompson, J. S., Schneider, P., Kalled, S. L., Wang, L., Lefevre, E. A., Cachero, T. G., MacKay, F., Bixler, S. A., Zafari, M., Liu, Z. Y., Woodcock, S. A., Qian, F., Batten, M., Madry, C., Richard, Y., Benjamin, C. D., Browning, J. L., Tsapis, A., Tschopp, J., \& Ambrose, C. (2000). BAFF binds to the tumor necrosis factor receptor-like molecule B cell maturation antigen and is important for maintaining the peripheral B cell population. The Journal of experimental medicine, 192(1), 129135. https://doi.org/10.1084/jem.192.1.129

36.Sasaki, Y., Casola, S., Kutok, J. L., Rajewsky, K., \& Schmidt-Supprian, M. (2004). TNF family member B cell-activating factor (BAFF) receptor-dependent and-independent roles for BAFF in B cell physiology. The Journal of Immunology, 173(4), 2245-2252.

37.Seshasayee, D., Valdez, P., Yan, M., Dixit, V. M., Tumas, D., \& Grewal, I. S. (2003). Loss of TACI causes fatal lymphoproliferation and autoimmunity, establishing TACI as an inhibitory BLyS receptor. Immunity, 18(2), 279-288. 
38.Darce, J. R., Arendt, B. K., Chang, S. K., \& Jelinek, D. F. (2007). Divergent effects of BAFF on human memory B cell differentiation into Ig-secreting cells. The Journal of Immunology, 178(9), $5612-5622$.

39..Day, E. S., Cachero, T. G., Qian, F., Sun, Y., Wen, D., Pelletier, M., ... \& Whitty, A. (2005). Selectivity of BAFF/BLyS and APRIL for binding to the TNF family receptors BAFFR/BR3 and BCMA. Biochemistry, 44(6), 1919-1931.

40.Rennert, P., Schneider, P., Cachero, T. G., Thompson, J., Trabach, L., Hertig, S., ... \& Tschopp, J. (2000). A soluble form of B cell maturation antigen, a receptor for the tumor necrosis factor family member APRIL, inhibits tumor cell growth. Journal of Experimental Medicine, 192(11), $1677-1684$

41.Moreaux, J., Sprynski, A. C., Dillon, S. R., Mahtouk, K., Jourdan, M., Ythier, A., ... \& Klein, B. (2009). APRIL and TACI interact with syndecan-1 on the surface of multiple myeloma cells to form an essential survival loop. European journal of haematology, 83(2), 119-129.

42.Avery, D. T., Kalled, S. L., Ellyard, J. I., Ambrose, C., Bixler, S. A., Thien, M., ... \& Tangye, S. G. (2003). BAFF selectively enhances the survival of plasmablasts generated from human memory B cells. The Journal of clinical investigation, 112(2), 286-297.

43.Tai, Y. T., Mayes, P. A., Acharya, C., Zhong, M. Y., Cea, M., Cagnetta, A., ... \& Anderson, K. C. (2014). Novel anti-B-cell maturation antigen antibody-drug conjugate (GSK2857916) selectively induces killing of multiple myeloma. Blood, The Journal of the American Society of Hematology, 123(20), 3128-3138.

44.Eckhert, E., Hewitt, R., \& Liedtke, M. (2019). B-cell maturation antigen directed monoclonal antibody therapies for multiple myeloma. Immunotherapy, 11(9), 801-811.

45.Demchenko, Y. N., Glebov, O. K., Zingone, A., Keats, J. J., Bergsagel, P. L., \& Kuehl, W. M. (2010). Classical and/or alternative NF- $\kappa B$ pathway activation in multiple myeloma. Blood, The Journal of the American Society of Hematology, 115(17), 3541-3552.

46.Hua, H., Kong, Q., Zhang, H., Wang, J., Luo, T., \& Jiang, Y. (2019). Targeting mTOR for cancer therapy. Journal of hematology \& oncology, 12(1), 1-19. 
47.Tai, Y. T., \& Anderson, K. C. (2019). B cell maturation antigen (BCMA)-based immunotherapy for multiple myeloma. Expert opinion on biological therapy, 19(11), 1143-1156.

48.Pan, J., Sun, Y., Zhang, N., Li, J., Ta, F., Wei, W., ... \& Ai, L. (2017). Characteristics of BAFF and APRIL factor expression in multiple myeloma and clinical significance. Oncology letters, 14(3), 2657-2662.

49.Yaccoby, S., Pennisi, A., Li, X., Dillon, S. R., Zhan, F., Barlogie, B., \& Shaughnessy, J. D. (2008). Atacicept (TACI-Ig) inhibits growth of TACI high primary myeloma cells in SCID-hu mice and in coculture with osteoclasts. Leukemia, 22(2), 406-413.

50.Laurent, S. A., Hoffmann, F. S., Kuhn, P. H., Cheng, Q., Chu, Y., Schmidt-Supprian, M., ... \& Meinl, E. (2015). $\gamma$-Secretase directly sheds the survival receptor BCMA from plasma cells. Nature communications, 6(1), 1-12.

51.Hatzoglou, A., Roussel, J., Bourgeade, M. F., Rogier, E., Madry, C., Inoue, J., ... \& Tsapis, A. (2000). TNF receptor family member BCMA (B cell maturation) associates with TNF receptor-associated factor (TRAF) 1, TRAF2, and TRAF3 and activates NF- $\kappa$ B, elk-1, c-Jun N-terminal kinase, and p38 mitogen-activated protein kinase. The Journal of Immunology, 165(3), 1322-1330.

52.Hendriks, J., Planelles, L., de Jong-Odding, J., Hardenberg, G., Pals, S. T., Hahne, M., ... \& Medema, J. P. (2005). Heparan sulfate proteoglycan binding promotes APRIL-induced tumor cell proliferation. Cell Death \& Differentiation, 12(6), 637-648.

53.Cassinelli, G., Ronchetti, D., Laccabue, D., Mattioli, M., Cuccuru, G., Favini, E., ... \& Lanzi, C. (2009). Concomitant downregulation of proliferation/survival pathways dependent on FGF-R3, JAK2 and BCMA in human multiple myeloma cells by multi-kinase targeting. Biochemical pharmacology, 78(9), 1139-1147.

54.Shaffer, A. L., Emre, N. T., Lamy, L., Ngo, V. N., Wright, G., Xiao, W., ... \& Staudt, L. M. (2008). IRF4 addiction in multiple myeloma. Nature, 454(7201), 226-231.

55.Frigyesi, I., Adolfsson, J., Ali, M., Kronborg Christophersen, M., Johnsson, E., Turesson, I., ... 
\& Nilsson, B. (2014). Robust isolation of malignant plasma cells in multiple myeloma. Blood, The Journal of the American Society of Hematology, 123(9), 1336-1340.

56.Salem, D. A., Maric, I., Yuan, C. M., Liewehr, D. J., Venzon, D. J., Kochenderfer, J., \& Stetler-Stevenson, M. (2018). Quantification of B-cell maturation antigen, a target for novel chimeric antigen receptor T-cell therapy in myeloma. Leukemia research, 71, 106-111.

57.Seckinger, A., Delgado, J. A., Moser, S., Moreno, L., Neuber, B., Grab, A., ... \& Vu, M. D. (2017). Target expression, generation, preclinical activity, and pharmacokinetics of the BCMA-T cell bispecific antibody EM801 for multiple myeloma treatment. Cancer cell, 31(3), 396-410.

58.Lee, L., Bounds, D., Paterson, J., Herledan, G., Sully, K., Seestaller-Wehr, L. M., ... \& Yong, K. L. (2016). Evaluation of B cell maturation antigen as a target for antibody drug conjugate mediated cytotoxicity in multiple myeloma. British journal of haematology, 174(6), 911-922.

59.Ali, S. A., Shi, V., Maric, I., Wang, M., Stroncek, D. F., Rose, J. J., Brudno, J. N., Stetler-Stevenson, M., Feldman, S. A., Hansen, B. G., Fellowes, V. S., Hakim, F. T., Gress, R. E., \& Kochenderfer, J. N. (2016). T cells expressing an anti-B-cell maturation antigen chimeric antigen receptor cause remissions of multiple myeloma. Blood, 128(13), 1688-1700. https://doi.org/10.1182/blood-2016-04-711903

60.Brudno, J. N., Maric, I., Hartman, S. D., Rose, J. J., Wang, M., Lam, N., ... \& Kochenderfer, J. N. (2018). T cells genetically modified to express an anti-B-cell maturation antigen chimeric antigen receptor cause remissions of poor-prognosis relapsed multiple myeloma. Journal of Clinical Oncology, 36(22), 2267.

61.Friedman, K. M., Garrett, T. E., Evans, J. W., Horton, H. M., Latimer, H. J., Seidel, S. L., ... \& Morgan, R. A. (2018). Effective targeting of multiple B-cell maturation antigen-expressing hematological malignances by anti-B-cell maturation antigen chimeric antigen receptor $\mathrm{T}$ cells. Human gene therapy, 29(5), 585-601.

62.Gutierrez, M. J., Desiderio, S. V., Wang, N. Y., Darrah, E., Cappelli, L., Nino, G., ... \& Bingham, C. O. (2019). Soluble markers of antibody secreting cell function as predictors of infection risk in rheumatoid arthritis. Journal of immunology research, 2019. 
63.Ghermezi, M., Li, M., Vardanyan, S., Harutyunyan, N. M., Gottlieb, J., Berenson, A., ... \& Berenson, J. R. (2017). Serum B-cell maturation antigen: a novel biomarker to predict outcomes for multiple myeloma patients. Haematologica, 102(4), 785.

64.Dettman, E. J., Rigat, F., Albert, J., Barnard, R., Birchler, M., Deghenhardt, Y., ... \& Opalinska, J. (2018). Expression of myeloma cell and soluble B-cell maturation antigen (BCMA) in relapsed and refractory multiple myeloma patients treated with GSK2857916 in BMA117159. Blood, 132, 1977.

65.Sanchez, E., Gillespie, A., Tang, G., Ferros, M., Harutyunyan, N. M., Vardanyan, S., ... \& Berenson, J. R. (2016). Soluble B-cell maturation antigen mediates tumor-induced immune deficiency in multiple myeloma. Clinical Cancer Research, 22(13), 3383-3397.

66.Chen H, Li M, Xu N, Ng N, Sanchez E, Soof CM, Patil S, Udd K, Bujarski S, Cao J, Hekmati T, Ghermezi M, Zhou M, Wang EY, Tanenbaum EJ, Zahab B, Schlossberg R, Yashar MA, Wang CS, Tang GY, Spektor TM, Berenson JR. Serum B-cell maturation antigen (BCMA) reduces binding of anti-BCMA antibody to multiple myeloma cells. Leuk Res. 2019;81:62-6.

67.Pont, M. J., Hill, T., Cole, G. O., Abbott, J. J., Kelliher, J., Salter, A. I., ... \& Riddell, S. R. (2019). $\gamma$-Secretase inhibition increases efficacy of BCMA-specific chimeric antigen receptor $\mathrm{T}$ cells in multiple myeloma. Blood, 134(19), 1585-1597.

68.Kriegsmann, K., Kriegsmann, M., Cremer, M., Schmitt, M., Dreger, P., Goldschmidt, H., ... \& Hundemer, M. (2019). Cell-based immunotherapy approaches for multiple myeloma. British journal of cancer, 120(1), 38-44.

69.Mikkilineni, L., \& Kochenderfer, J. N. (2017). Chimeric antigen receptor T-cell therapies for multiple myeloma. Blood, 130(24), 2594-2602. https://doi.org/10.1182/blood-2017-06-793869.

70.Danhof, S., Hudecek, M., \& Smith, E. L. (2018). CARs and other T cell therapies for MM: the clinical experience. Best Practice \& Research Clinical Haematology, 31(2), 147-157.

71.Ghosh, A., Mailankody, S., Giralt, S. A., Landgren, C. O., Smith, E. L., \& Brentjens, R. J. (2018). CAR T cell therapy for multiple myeloma: where are we now and where are we headed?. Leukemia \& lymphoma, 59(9), 2056-2067. 
72.Smith, E. L., Staehr, M., Masakayan, R., Tatake, I. J., Purdon, T. J., Wang, X., ... \& Brentjens, R. J. (2018). Development and evaluation of an optimal human single-chain variable fragment-derived BCMA-targeted CAR T cell vector. Molecular Therapy, 26(6), 1447-1456.

73.Hoyos, V., \& Borrello, I. (2016). The immunotherapy era of myeloma: monoclonal antibodies, vaccines, and adoptive T-cell therapies. Blood, The Journal of the American Society of Hematology, 128(13), 1679-1687.

74.Raje, N., Berdeja, J., Lin, Y. I., Siegel, D., Jagannath, S., Madduri, D., ... \& Kochenderfer, J. N. (2019). Anti-BCMA CAR T-cell therapy bb2121 in relapsed or refractory multiple myeloma. New England Journal of Medicine, 380(18), 1726-1737.

75.Berdeja J, Alsina M, Shah N, Siegel D, Jagannath S, Madduri D, Kaufman JL, Munshi N, Rosenblatt J, Jasielec JK, Lin Y, Turka A, Lam LP, Massaro M, Campbell TB, Hege K, Petrocca F, Raje NS: Updated results from an ongoing phase 1 clinical study of bb21217 Anti-Bcma CAR T cell therapy. Blood 2019, 134(Supplement_1):927.

76.Munshi NC, Larry D, Anderson J, Shah N, Jagannath S, Berdeja JG, Lonial S, Raje NS, Siegel DSD, Lin Y, Oriol A, Moreau P, Yakoub-Agha I, Delforge M, Petrocca F, Connarn J, Patel P, Huang L, Campbell TB, Hege K, Miguel JS, Investigators obotKS: Idecabtagene vicleucel (ide-cel; bb2121), a BCMA-targeted CAR T-cell therapy, in patients with relapsed and refractory multiple myeloma (RRMM): Initial KarMMa results. J Clin Oncol 2020, 38(15_suppl):8503-8503.

77.Shah, N., Chari, A., Scott, E. et al. B-cell maturation antigen (BCMA) in multiple myeloma: rationale for targeting and current therapeutic approaches. Leukemia 34, 985-1005 (2020). https://doi.org/10.1038/s41375-020-0734-Z

78.Zhao, W. H., Liu, J., Wang, B. Y., Chen, Y. X., Cao, X. M., Yang, Y., Zhang, Y. L., Wang, F. X., Zhang, P. Y., Lei, B., Gu, L. F., Wang, J. L., Yang, N., Zhang, R., Zhang, H., Shen, Y., Bai, J., Xu, Y., Wang, X. G., Zhang, R. L., ... Zhang, W. G. (2018). A phase 1, open-label study of LCAR-B38M, a chimeric antigen receptor $\mathrm{T}$ cell therapy directed against $\mathrm{B}$ cell maturation antigen, in patients with relapsed or refractory multiple myeloma. Journal of hematology \& oncology, 11(1), 


\section{1. https://doi.org/10.1186/s13045-018-0681-6.}

79.Xu, J., Chen, L. J., Yang, S. S., Sun, Y., Wu, W., Liu, Y. F., ... \& Chen, S. J. (2019). Exploratory trial of a biepitopic CAR T-targeting B cell maturation antigen in relapsed/refractory multiple myeloma. Proceedings of the National Academy of Sciences, 116(19), 9543-9551.

80.Chen, L., Xu, J., Fu Sr, W., Jin, S., Yang, S., Yan, S., ... \& Mi, J. Q. (2019). Updated phase 1 results of a first-in-human open-label study of Lcar-B38M, a structurally differentiated chimeric antigen receptor $\mathrm{T}(\mathrm{CAR}-\mathrm{T})$ cell therapy targeting $\mathrm{B}$-cell maturation antigen (BCMA).

81.Li, C., Wang, J., Wang, D., Hu, G., Yang, Y., Zhou, X., ... \& Zhou, J. (2019). Efficacy and safety of fully human Bcma targeting CAR T cell therapy in relapsed/refractory multiple myeloma.

82.Li, C., Zhou, X., Wang, J., Hu, G., Meng, L., Hong, Z., ... \& Zhou, J. (2019). Clinical responses and pharmacokinetics of fully human BCMA targeting CAR T cell therapy in relapsed/refractory multiple myeloma. Clinical Lymphoma, Myeloma and Leukemia, 19(10), e23-e24.

83.Lin, L., Cho, S. F., Xing, L., Wen, K., Li, Y., Yu, T., ... \& Tai, Y. T. (2021). Preclinical evaluation of CD8+ anti-BCMA mRNA CAR T cells for treatment of multiple myeloma. Leukemia, $35(3), 752-763$.

84.Sommer, C., Boldajipour, B., Kuo, T. C., Bentley, T., Sutton, J., Chen, A., ... \& Sasu, B. J. (2019). Preclinical evaluation of allogeneic CAR T cells targeting BCMA for the treatment of multiple myeloma. Molecular therapy, 27(6), 1126-1138.

85.Han, X., Wang, Y., Wei, J., \& Han, W. (2019). Multi-antigen-targeted chimeric antigen receptor $\mathrm{T}$ cells for cancer therapy. Journal of hematology \& oncology, 12(1), 1-10.

86.Jia, H., Wang, Z., Wang, Y., Liu, Y., Dai, H., Tong, C., ... \& Han, W. (2019). Haploidentical CD19/CD22 bispecific CAR-T cells induced MRD-negative remission in a patient with relapsed and refractory adult B-ALL after haploidentical hematopoietic stem cell transplantation. Journal of hematology \& oncology, 12(1), 1-9.

87.Zhang, H., Gao, L., Liu, L., Wang, J., Wang, S., Gao, L., ... \& Zhang, X. (2019). A Bcma and CD19 bispecific CAR-T for relapsed and refractory multiple myeloma. 
88.Morandi, F., Horenstein, A. L., Costa, F., Giuliani, N., Pistoia, V., \& Malavasi, F. (2018). CD38: a target for immunotherapeutic approaches in multiple myeloma. Frontiers in immunology, 9, 2722.

89.Ma, X., Wong, S. W., Zhou, P., Chaulagain, C. P., Doshi, P., Klein, A. K., ... \& Comenzo, R. L. (2018). Daratumumab binds to mobilized CD34+ cells of myeloma patients in vitro without cytotoxicity or impaired progenitor cell growth. Experimental hematology \& oncology, 7(1), 1-10.

90.Usmani, S. Z., Khan, I., Chiu, C., Foureau, D., Druhan, L. J., Rigby, K., ... \& Sasser, A. K. (2018). Deep sustained response to daratumumab monotherapy associated with T-cell expansion in triple refractory myeloma. Experimental hematology \& oncology, 7(1), 1-7.

91.Li, C., Mei, H., Hu, Y., Guo, T., Liu, L., Jiang, H., ... \& Jin, D. (2019). A bispecific CAR-T cell therapy targeting Bcma and CD38 for relapsed/refractory multiple myeloma: updated results from a phase 1 dose-climbing trial.

92.Lee, L., Draper, B., Chaplin, N., Philip, B., Chin, M., Galas-Filipowicz, D., ... \& Pule, M. (2018). An APRIL-based chimeric antigen receptor for dual targeting of BCMA and TACI in multiple myeloma. Blood, The Journal of the American Society of Hematology, 131(7), 746-758.

93.Chen, K. H., Wada, M., Pinz, K. G., Liu, H., Shuai, X., Chen, X., ... \& Ma, Y. (2018). A compound chimeric antigen receptor strategy for targeting multiple myeloma. Leukemia, 32(2), 402-412.

94.Lonial, S., Dimopoulos, M., Palumbo, A., White, D., Grosicki, S., Spicka, I., ... \& Richardson, P. (2015). Elotuzumab therapy for relapsed or refractory multiple myeloma. New England Journal of Medicine, 373(7), 621-631.

95.Chu, J., Deng, Y., Benson, D. M., He, S., Hughes, T., Zhang, J., ... \& Yu, J. (2014). CS1-specific chimeric antigen receptor (CAR)-engineered natural killer cells enhance in vitro and in vivo antitumor activity against human multiple myeloma. Leukemia, 28(4), 917-927.

96.Fu Sr, W., Du, J., Jiang, H., Cheng, Z., Wei, R., Yu, K., ... \& Wang, P. (2019). Efficacy and safety of CAR-T therapy with safety switch targeting BCMA for patients with relapsed/refractory multiple myeloma in a phase 1 clinical study. 
97.Mailankody, S., Ghosh, A., Staehr, M., Purdon, T. J., Roshal, M., Halton, E., ... \& Smith, E. L. (2018). Clinical responses and pharmacokinetics of MCARH171, a human-derived Bcma targeted CAR T cell therapy in relapsed/refractory multiple myeloma: final results of a phase I clinical trial.

98.Green, D. J., Pont, M., Sather, B. D., Cowan, A. J., Turtle, C. J., Till, B. G., ... \& Riddell, S. R. (2018). Fully human Bcma targeted chimeric antigen receptor $\mathrm{T}$ cells administered in a defined composition demonstrate potency at low doses in advanced stage high risk multiple myeloma. Blood, 132, 1011.

99.Mailankody, S., Htut, M., Lee, K. P., Bensinger, W., Devries, T., Piasecki, J., ... \& Jakubowiak, A. (2018). JCARH125, anti-BCMA CAR T-cell therapy for relapsed/refractory multiple myeloma: initial proof of concept results from a phase 1/2 multicenter study (EVOLVE). Blood, 132, 957.

100.Cohen, A. D., Garfall, A. L., Stadtmauer, E. A., Melenhorst, J. J., Lacey, S. F., Lancaster, E., ... \& Milone, M. C. (2019). B cell maturation antigen-specific CAR T cells are clinically active in multiple myeloma. The Journal of clinical investigation, 129(6), 2210-2221.

101.Adams, G. B., Feng, J., Ghogha, A., Mardiros, A., Rodriguez, R., Spindler, T. J., ... \& Polverino, T. (2017). Selectivity and specificity of engineered T cells expressing KITE-585, a chimeric antigen receptor targeting B-cell maturation antigen (BCMA).

102.Adams, G. B., Feng, J., Ghogha, A., Mardiros, A., Murakami, J., Phung, T., ... \& Polverino, T. (2017). Development of KITE-585: a fully human BCMA CAR T-cell therapy for the treatment of multiple myeloma.

103.Cornell, R. F., Locke, F. L., Bishop, M. R., Orlowski, R. Z., Larson, S. M., Borrello, I., ... \& Roberts, Z. (2018). A phase 1 multicenter study evaluating KITE-585, an autologous anti-BCMA CAR T-cell therapy, in patients with relapsed/refractory multiple myeloma.

104.Zhao, S., Jiang, E., Chen, S., Gu, Y., Shangguan, A. J., Lv, T., ... \& Yu, Z. (2016). PiggyBac transposon vectors: the tools of the human gene encoding. Translational lung cancer research, 5(1), 120. 
105.Hermanson, D. L., Barnett, B. E., Rengarajan, S., Codde, R., Wang, X., Tan, Y., ... \& Shedlock, D. J. (2016). A novel BCMA-specific, centyrin-based CAR-T product for the treatment of multiple myeloma. Blood, 128(22), 2127.

106.Le Ray, E., Jagannath, S., \& Palumbo, A. (2016). Advances in targeted therapy for the treatment of patients with relapsed/refractory multiple myeloma. Expert review of hematology, 9(1), 91-105.

107.Liu, J., Liu, W., Mi, L., Zeng, X., Cai, C., Ma, J., \& Wang, L. (2019). Union for China Lymphoma Investigators of the Chinese Society of Clinical O, Union for China Leukemia Investigators of the Chinese Society of Clinical O: Incidence and mortality of multiple myeloma in China, 2006-2016: an analysis of the Global Burden of Disease Study 2016. J Hematol Oncol, 12(1), 136.

108.Liu, W., Liu, J., Song, Y., Wang, X., Zhou, M., Wang, L., ... \& Zhu, J. (2019). Union for China Leukemia Investigators of the Chinese Society of Clinical Oncology UfCLIotCSoCO: mortality of lymphoma and myeloma in China, 2004-2017: an observational study. J Hematol Oncol, 12(1), 22.

109.Lokhorst, H. M., Plesner, T., Laubach, J. P., Nahi, H., Gimsing, P., Hansson, M., Minnema, M. C., Lassen, U., Krejcik, J., Palumbo, A., van de Donk, N. W., Ahmadi, T., Khan, I., Uhlar, C. M., Wang, J., Sasser, A. K., Losic, N., Lisby, S., Basse, L., Brun, N., ... Richardson, P. G. (2015). Targeting CD38 with Daratumumab Monotherapy in Multiple Myeloma. The New England journal of medicine, 373(13), 1207-1219. https://doi.org/10.1056/NEJMoa1506348

110.Usmani, S., Ahmadi, T., Ng, Y., Lam, A., Desai, A., Potluri, R., \& Mehra, M. (2016). Analysis of Real-World Data on Overall Survival in Multiple Myeloma Patients With $\geq 3$ Prior Lines of Therapy Including a Proteasome Inhibitor (PI) and an Immunomodulatory Drug (IMiD), or Double Refractory to a PI and an IMiD. The oncologist, 21(11), 1355-1361. https://doi.org/10.1634/theoncologist.2016-0104

111.Gregory, T., Cohen, A. D., Costello, C. L., Ali, S. A., Berdeja, J. G., Ostertag, E. M., ... \& Patel, K. K. (2018). Efficacy and safety of P-Bcma-101 CAR-T cells in patients with relapsed/refractory (r/r) multiple myeloma (MM). Blood, 132, 1012.

112.Costello, C. L., Gregory, T. K., Ali, S. A., Berdeja, J. G., Patel, K. K., Shah, N. D., Ostertag, E., 
Martin, C., Ghoddusi, M., Shedlock, D. J., Spear, M. A., Orlowski, R. Z., \& Cohen, A. D. (2019). Phase 2 Study of the Response and Safety of P-Bcma-101 CAR-T Cells in Patients with Relapsed/Refractory (r/r) Multiple Myeloma (MM) (PRIME). Blood, 134(Supplement_1), 3184. https://doi.org/10.1182/blood-2019-129562.

113.Jie, J., Hao, S., Jiang, S., Li, Z., Yang, M., Zhang, W., Yu, K., Xiao, J., Meng, H., Ma, L., He, M., WANG, W., Huang, X., Chen, L., Xing, C., Yuan, D., Wang, S., Tao, R., Dai, L., \& Ma, H. (2019). Phase 1 Trial of the Safety and Efficacy of Fully Human Anti-Bcma CAR T Cells in Relapsed/Refractory Multiple Myeloma. Blood, 134(Supplement_1), 4435. https://doi.org/10.1182/blood-2019-126104

114.Jiang, S., Jin, J., Hao, S., Yang, M., Chen, L., Ruan, H., Xiao, J., Wang, W., Li, Z., \& Yu, K. (2018). Low Dose of Human scFv-Derived BCMA-Targeted CAR-T Cells Achieved Fast Response and High Complete Remission in Patients with Relapsed/Refractory Multiple Myeloma. Blood, 132(Supplement 1), 960. https://doi.org/10.1182/blood-2018-99-113220.

115.Jiang, H., Zhang, W., Shang, P., Zhang, H., Fu, W., Ye, F., Zeng, T., Huang, H., Zhang, X., Sun, W., Man-Yuen Sze, D., Yi, Q., \& Hou, J. (2013). Transfection of chimeric anti-CD138 gene enhances natural killer cell activation and killing of multiple myeloma cells. Molecular Oncology, 8(2), 297-310. https://doi.org/10.1016/j.molonc.2013.12.001

116.Chu, J., Deng, Y., Benson, D. M., He, S., Hughes, T., Zhang, J., ... \& Yu, J. (2014). CS1-specific chimeric antigen receptor (CAR)-engineered natural killer cells enhance in vitro and in vivo antitumor activity against human multiple myeloma. Leukemia, 28(4), 917-927.

117.Kumar, S. K., Rajkumar, V., Kyle, R. A., van Duin, M., Sonneveld, P., Mateos, M. V., Gay, F., \& Anderson, K. C. (2017). Multiple myeloma. Nature Reviews Disease Primers, 3(1). https://doi.org/10.1038/nrdp.2017.46

118.Chim, C. S., Kumar, S. K., Orlowski, R. Z., Cook, G., Richardson, P. G., Gertz, M. A., ... \& 
Anderson, K. C. (2018). Management of relapsed and refractory multiple myeloma: novel agents, antibodies, immunotherapies and beyond. Leukemia, 32(2), 252-262.

119.D’Agostino, M., Boccadoro, M., \& Smith, E. L. (2017). Novel Immunotherapies for Multiple Myeloma. Current Hematologic Malignancy Reports, 12(4), 344-357. https://doi.org/10.1007/s11899-017-0397-7

120.Xu, J., Wang, Q., Xu, H., Gu, C., Jiang, L., Wang, J., Wang, D., Xu, B., Mao, X., Wang, J., Wang, Z., Xiao, Y., Zhang, Y., Li, C., \& Zhou, J. (2018). Anti-BCMA CAR-T cells for treatment of plasma cell dyscrasia: case report on POEMS syndrome and multiple myeloma. Journal of Hematology \& Oncology, 11(1). https://doi.org/10.1186/s13045-018-0672-7.

121.Xu, J., Chen, L. J., Yang, S. S., Sun, Y., Wu, W., Liu, Y. F., Xu, J., Zhuang, Y., Zhang, W., Weng, X. Q., Wu, J., Wang, Y., Wang, J., Yan, H., Xu, W. B., Jiang, H., Du, J., Ding, X. Y., Li, B., . . . Chen, S. J. (2019). Exploratory trial of a biepitopic CAR T-targeting B cell maturation antigen in relapsed/refractory multiple myeloma. Proceedings of the National Academy of Sciences, 116(19), 9543-9551. https://doi.org/10.1073/pnas.1819745116

122. Nie, Y., Lu, W., Chen, D., Tu, H., Guo, Z., Zhou, X., Li, M., Tu, S., \& Li, Y. (2020). Mechanisms underlying CD19-positive ALL relapse after anti-CD19 CAR T cell therapy and associated strategies. Biomarker Research, 8(1). https://doi.org/10.1186/s40364-020-00197-1.

123. Brudno, J. N., \& Kochenderfer, J. N. (2016). Toxicities of chimeric antigen receptor T cells: recognition and management. Blood, The Journal of the American Society of Hematology, 127(26), 3321-3330.

124. Teachey, D. T., Lacey, S. F., Shaw, P. A., Melenhorst, J. J., Maude, S. L., Frey, N., ... \& Grupp, S. A. (2016). Identification of predictive biomarkers for cytokine release syndrome after chimeric antigen receptor T-cell therapy for acute lymphoblastic leukemia. Cancer discovery, 6(6), 664-679.

125. Teachey, D. T., Rheingold, S. R., Maude, S. L., Zugmaier, G., Barrett, D. M., Seif, A. E., ... \& 
Grupp, S. A. (2013). Cytokine release syndrome after blinatumomab treatment related to abnormal macrophage activation and ameliorated with cytokine-directed therapy. Blood, The Journal of the American Society of Hematology, 121(26), 5154-5157.

126. Quintarelli, C., Vera, J. F., Savoldo, B., Giordano Attianese, G. M. P., Pule, M., Foster, A. E., Heslop, H. E., Rooney, C. M., Brenner, M. K., \& Dotti, G. (2007). Co-expression of cytokine and suicide genes to enhance the activity and safety of tumor-specific cytotoxic T lymphocytes. Blood, 110(8), 2793-2802. https://doi.org/10.1182/blood-2007-02-072843

127. Di Stasi, A., Tey, S. K., Dotti, G., Fujita, Y., Kennedy-Nasser, A., Martinez, C., ... \& Brenner, M. K. (2011). Inducible apoptosis as a safety switch for adoptive cell therapy. N Engl J Med, 365, 1673-1683.

128. Ramos, C. A., Asgari, Z., Liu, E., Yvon, E., Heslop, H. E., Rooney, C. M., ... \& Dotti, G. (2010). An inducible caspase 9 suicide gene to improve the safety of mesenchymal stromal cell therapies. Stem cells, 28(6), 1107-1115.

129. Fedorov, V. D., Themeli, M., \& Sadelain, M. (2013). PD-1-and CTLA-4-based inhibitory chimeric antigen receptors (iCARs) divert off-target immunotherapy responses. Science translational medicine, 5(215), 215ra172-215ra172.

130. Juillerat, A., Marechal, A., Filhol, J. M., Valton, J., Duclert, A., Poirot, L., \& Duchateau, P. (2016). Design of chimeric antigen receptors with integrated controllable transient functions. Scientific reports, 6(1), 1-7.

131. Wu, C. Y., Roybal, K. T., Puchner, E. M., Onuffer, J., \& Lim, W. A. (2015). Remote control of therapeutic T cells through a small molecule-gated chimeric receptor. Science, 350(6258).

132. Quazi, S. (2021). Vaccine in response to COVID-19: Recent developments, challenges, and a way out. Biomedical And Biotechnology Research Journal (BBRJ), 5(2), 105-109. Doi:

10.4103/bbrj.bbrj_166_20 
